Article

\title{
Construction of Charring-Functional Polyheptanazine towards Improvements in Flame Retardants of Polyurethane
}

\author{
Shaolin Lu, Botao Shen and Xudong Chen * D
}

Key Laboratory for Polymeric Composite and Functional Materials of Ministry of Education, School of Chemistry, Sun Yat-sen University, Guangzhou 510275, China; lushlin@mail2.sysu.edu.cn (S.L.); shenbt@mail2.sysu.edu.cn (B.S.)

* Correspondence: cescxd@mail.sysu.edu.cn; Tel.: +86-20-8411-3498

check for updates

Citation: Lu, S.; Shen, B.; Chen, X. Construction of Charring-Functional Polyheptanazine towards Improvements in Flame Retardants of Polyurethane. Molecules 2021, 26, 340. https://doi.org/10.3390/molecules 26020340

Received: 20 October 2020 Accepted: 21 December 2020 Published: 11 January 2021

Publisher's Note: MDPI stays neutral with regard to jurisdictional clai$\mathrm{ms}$ in published maps and institutional affiliations.

Copyright: (C) 2021 by the authors. Licensee MDPI, Basel, Switzerland. This article is an open access article distributed under the terms and conditions of the Creative Commons Attribution (CC BY) license (https:// creativecommons.org/licenses/by/ $4.0 /)$.

\begin{abstract}
Nitrogen-containing flame retardants have been extensively applied due to their low toxicity and smoke-suppression properties; however, their poor charring ability restricts their applications. Herein, a representative nitrogen-containing flame retardant, polyheptanazine, was investigated. Two novel, cost-effective phosphorus-doped polyheptazine (PCN) and cobalt-anchored PCN (Co@PCN) flame retardants were synthesized via a thermal condensation method. The X-ray photoelectron spectroscopy (XPS) results indicated effective doping of $P$ into triazine. Then, flame-retardant particles were introduced into thermoplastic polyurethane (TPU) using a melt-blending approach. The introduction of $3 \mathrm{wt} \% \mathrm{PCN}$ and Co@PCN could remarkably suppress peak heat release rate (pHRR) (48.5\% and $40.0 \%)$, peak smoke production rate (pSPR) $(25.5 \%$ and $21.8 \%)$, and increasing residues $(10.18 \mathrm{wt} \% \rightarrow 17.04 \mathrm{wt} \%$ and $14.08 \mathrm{wt} \%)$. Improvements in charring stability and flame retardancy were ascribed to the formation of $\mathrm{P}-\mathrm{N}$ bonds and $\mathrm{P}=\mathrm{N}$ bonds in triazine rings, which promoted the retention of $\mathrm{P}$ in the condensed phase, which produced additional high-quality residues.
\end{abstract}

Keywords: flame retardants; thermoplastic polyurethane; phosphorous doped; polyheptanazine; thermal decomposition

\section{Introduction}

Nitrogen-containing compounds are used as halogen-free flame retardants for polymers due to their low toxicity and smoke suppression during fires [1]. Nitrogen-containing compounds improve flame retardancy mainly by diluting the concentration of oxygen and by encouraging the dripping of a polymer [2,3]. However, the poor flame-retardant efficiency of nitrogen-containing flame retardants restricts their applications. Inspired by the condensed-phase flame retardancy mechanism, the formation of more char residues in the condensed phase is a superior way to reduce the heat release rate (HRR) during combustion.

Triazine-based compounds are halogen-free flame retardants frequently used for thermoplastic polyurethane (TPU) because of their smoke suppression during combustion and their low toxicity [4,5]. Most triazine-based flame retardants decompose to produce noncombustible gases, which act as gas-phase flame retardants [6]. Polyheptazines, derivatives of triazine flame retardants, promote a condensed-phase flame retardancy mechanism by forming a physical barrier in a polymer matrix [7-9]. All of these flame-retardant systems have demonstrated that no reaction occurs between flame retardants and the polymer matrix during degradation, which does not change the residue production. Thus, it is important to investigate methods to realize charring of the condensed phase without changing the two-dimensional framework of polyheptanazine. Recent studies have demonstrated that phosphorus doping can improve the thermo-oxidative stability of graphene oxide (GO) and reduced graphene oxide (rGO) [10]. Polyheptanazine contains nitrogen triangles with six lone-pairs of electrons, which are available for doping [11]. Phosphorus can be used in flame retardants and may replace the halogenated variants currently in 
use [12]. Research on P-containing flame retardants is increasing due to environmental pollution caused by halogenated flame retardants $[13,14]$. A variety of halogen-free flame retardants for polymers have been developed, most of which contain P [15-18]. In recent years, phosphorus-doped polyheptazines have attracted increasing attention due to their applications in wastewater treatment [19], photocatalysts [20,21], electrocatalysts [22], organic matter degradation [23,24], and bioimaging [25]. According to the literature [12], compounds containing $\mathrm{P}-\mathrm{N}$ bonds can promote the formation of more stable char residues due to the formation of a crosslinked network between $\mathrm{P}-\mathrm{N}$ bond compounds and polymer chains during combustion. Therefore, it is speculated that $\mathrm{P}-\mathrm{N}$ bonds can be formed by controlling interstitial $\mathrm{P}$ doping to obtain more effective polyheptazine flame retardants.

Transition metals can also improve the flame retardancy of TPU [26,27]. Shi et al. [28] prepared spinel copper cobaltate/polyheptazine nanohybrids $\left(\mathrm{C}-\mathrm{CuCo}_{2} \mathrm{O}_{4}\right)$ via a hydrothermal method. The results showed that the introduction of $\mathrm{C}-\mathrm{CuCo}_{2} \mathrm{O}_{4}$ into TPU achieved a flame-retardant effect and reduced the release of toxic gases. In his other work, polystyrene/g- $\mathrm{C}_{3} \mathrm{~N}_{4} / \mathrm{ZnCo}_{2} \mathrm{O}_{4}$ composites were prepared [29], and the results showed that the introduction of hybrids enhanced the thermal stability of PS during catalysis. The introduction of a Co compound into the polymer can reduce the evolution of aromatic compounds, which means the reduction of toxic organic volatiles [30,31]. Many studies have shown that Co can improve the charring property of polymers and can suppress the release of toxic gases during degradation [32]. It has been reported that an abundance of $\mathrm{N}$ atoms on the surface of polyheptanazine provides a tremendous number of adsorption sites for anchoring metal ions [22]. Generally, analogous to $\mathrm{Fe}-\mathrm{N}$ bonds [33], the specific interactions between $\mathrm{Co}-\mathrm{N}$ bonds is useful for improving water oxidation [34].

To enhance the effect of condensed-phase flame retardancy of polyheptazine $(\mathrm{CN})$, a phosphorus-doped polyheptanazine ( $\mathrm{PCN})$ was prepared by using the diammonium hydrogen phosphate as the P source and urea as the polyheptazine precursor. After further heat treatment with cobalt acetate, Co was successfully anchored on the surface of phosphorusdoped polyheptazine (Co@PCN). Afterward, these flame-retardant particles were incorporated into TPU, and then the thermal stability and fire hazards of the nanocomposites were investigated. Introducing P and Co is expected to improve the poor condensed-phase flame retardancy typically observed in nitrogen-containing flame retardants.

\section{Results and Discussion}

\subsection{Characterization of PCN and $\mathrm{Co} @ P C N$}

As shown in Figure 1a, Fourier-transform infrared (FTIR) spectroscopy was used to define the functional groups and chemical species in the prepared particles. In general, the original $\mathrm{CN}$ contains three typical vibration bands, included $\mathrm{N}-\mathrm{H}$ and $\mathrm{C}-\mathrm{N}$ bonds, located around $3200 \mathrm{~cm}^{-1}$ and $1200-1650 \mathrm{~cm}^{-1}$, respectively. The third peak was detected at $814 \mathrm{~cm}^{-1}$, which was caused by the out-of-plane bending vibration of heptanazine rings [35]. The vibrational bands of $\mathrm{P}-\mathrm{N}$ functional groups of PCN and $\mathrm{Co} @ \mathrm{PCN}$ were not detected, which may be due to the overlap of these vibrational bands with strong $\mathrm{C}-\mathrm{N}$ vibrational bands [36-38]. Nevertheless, a small wavenumber shift occurred in the sharp band around $814 \mathrm{~cm}^{-1}$ (Figure $1 \mathrm{~b}$ ), indicating a change in the electron cloud in $\mathrm{C}-\mathrm{N}$ bonds and $\mathrm{C}=\mathrm{N}$ bonds induced by phosphorus doping [39]. A similar phenomenon was also observed in Co@PCN. There was also a new band at $495 \mathrm{~cm}^{-1}$ in PCN and Co@PCN, which originated from the P-O-P bending mode [40]. The crystal structure and phase purity of PCN and Co@PCN were assessed by X-ray diffraction (XRD) using CN as a reference sample. The results are shown in Figure 1c. The pattern of $\mathrm{CN}$ had two characteristic peaks. The peak at $12.97^{\circ}$ was caused by in-plane repeating units at, and the other one at $27.73^{\circ}$ originated from the interlayer stacking of conjugated aromatic units [35]. The PCN particles showed a similar XRD pattern to the original polyheptanazine, which indicates that polyheptanazine retained its framework well during the phosphorization process. However, there were some small sharp peaks in the P-doped samples, indicating that the samples may contain crystalline phosphate impurities $[23,40,41]$. In addition, the 
weakening of the PCN (002) diffraction peak may be caused by the inclusion of heteroelement $\mathrm{P}$ during thermal phosphorization, which enlarged the interlayer spacing and reduced the thickness of the graphitic structure. The further decrease in the diffraction intensity of metal-containing samples (Co@PCN) may be attributed to chemical coupling between PCN and metal phosphide clusters [35,42]. Figure 1d shows the TG-DSC curve of a mixture of urea and diammonium hydrogen phosphate (DHP). The endothermic peak of the mixture at $134^{\circ} \mathrm{C}$ was the melting of urea. The melting point of DHP is about $155^{\circ} \mathrm{C}$. Figure $1 \mathrm{~d}$ shows that urea and DHP began to react at $150-230^{\circ} \mathrm{C}$. The corresponding peak at $237^{\circ} \mathrm{C}$ was due to the formation of a triazine structure. The polymerization of the triazine compound occurred at $364^{\circ} \mathrm{C}$, which was earlier than the similar peak temperature of $\mathrm{CN}$ prepared using pristine urea [3]. The residues of the mixture of urea and DHP were $3.8 \%$ at $550{ }^{\circ} \mathrm{C}$ from the curves of TG-DSC (Simultaneous thermogravimetric analysis coupled with differential scanning calorimeter) The obtained product yield (PCN) was about $5.2 \%$ from calcination in muffle furnace. The reason for the differences may be due to the different environments in which mixture were located.

a)

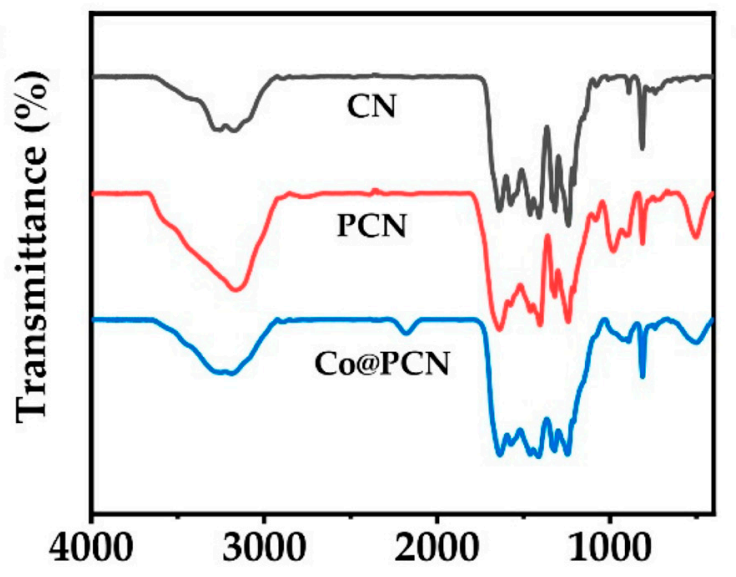

Wavenumber $\left(\mathrm{cm}^{-1}\right)$

c)

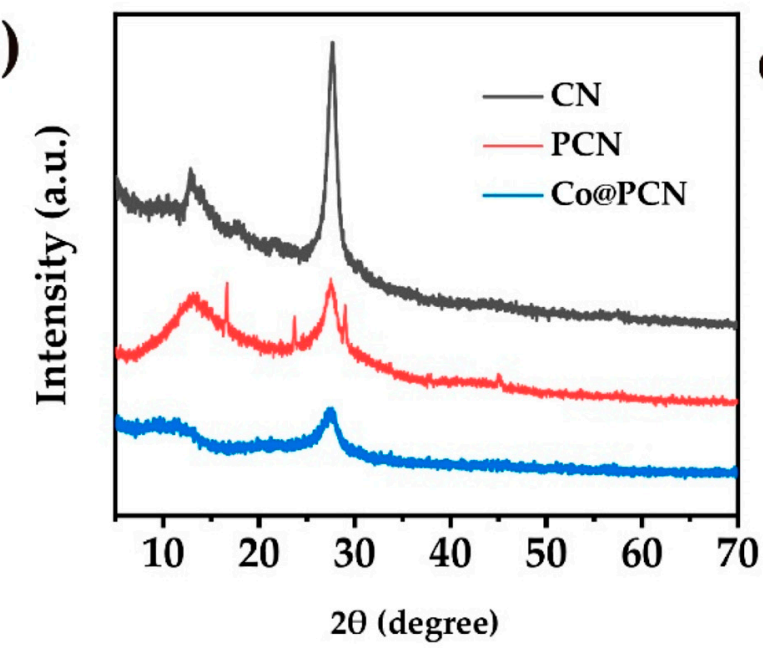

b)

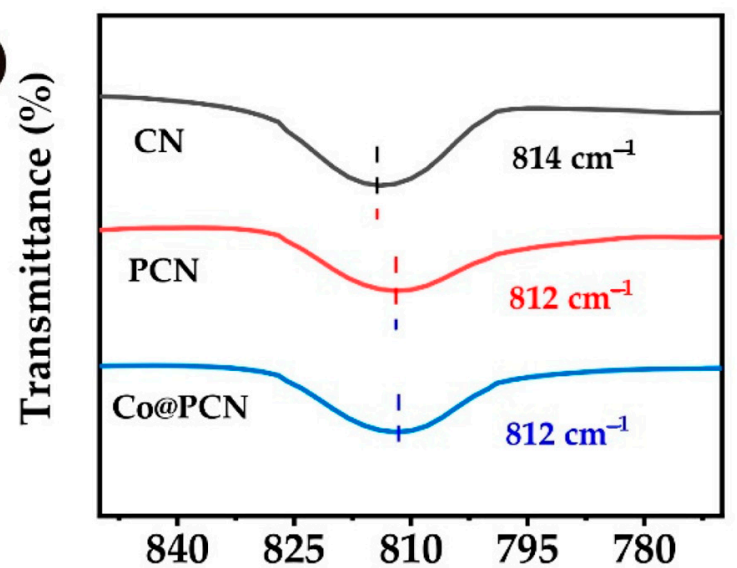

Wavenumber $\left(\mathrm{cm}^{-1}\right)$

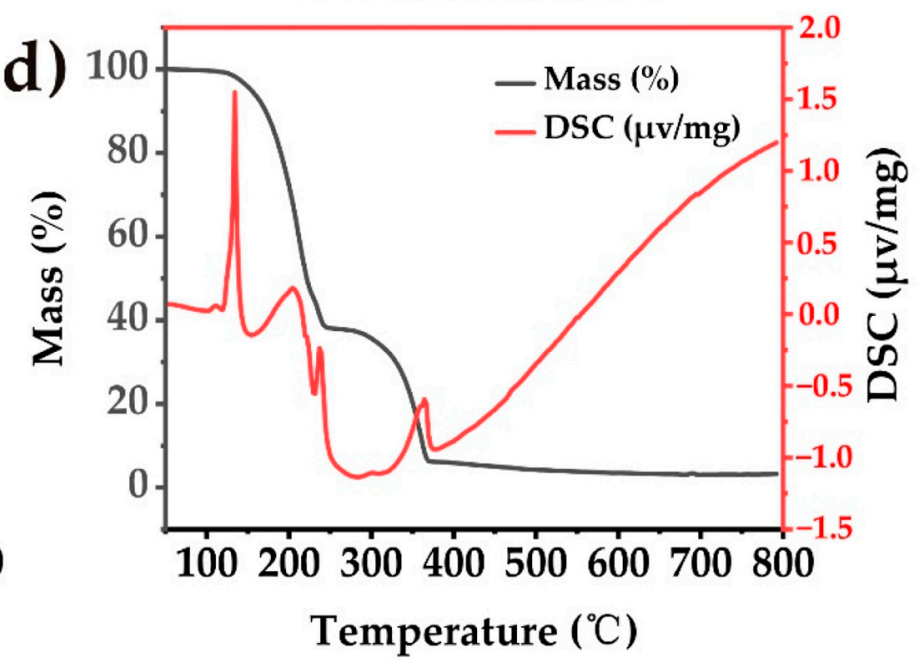

Figure 1. (a) FT-IR spectra and (c) XRD patterns of CN, PCN, and Co/PCN. (b) A closer investigation over the absorption peak centered at around $814 \mathrm{~cm}^{-1}$. (d) TG-DSC curves of the mixture of urea and $(\mathrm{NH} 4)_{2} \cdot \mathrm{HPO}_{4}$ in air atmosphere.

As shown in Figure 2, similar to that of $\mathrm{CN}$ and PCN, Co@PCN still presented a distinct nanosheet structure. The composition of chemical species in Co@PCN particles was further investigated using scanning transmission electron microscope (STEM) and energy-dispersive spectrum mapping (EDS) analysis. Significantly, P and Co showed analogous distribution patterns as N (Figure 2h,i), which demonstrated effective doping of 
P into the triazine rings of $\mathrm{CN}$. We did not observe nanoclusters on the surface of Co@PCN. It should be noted that the low-density distribution of Co suggested that there were other forms of CoP or cobalt oxides besides the nanoclusters. A considerable part of these may be only sub-nanometer or even atomic in size [35].
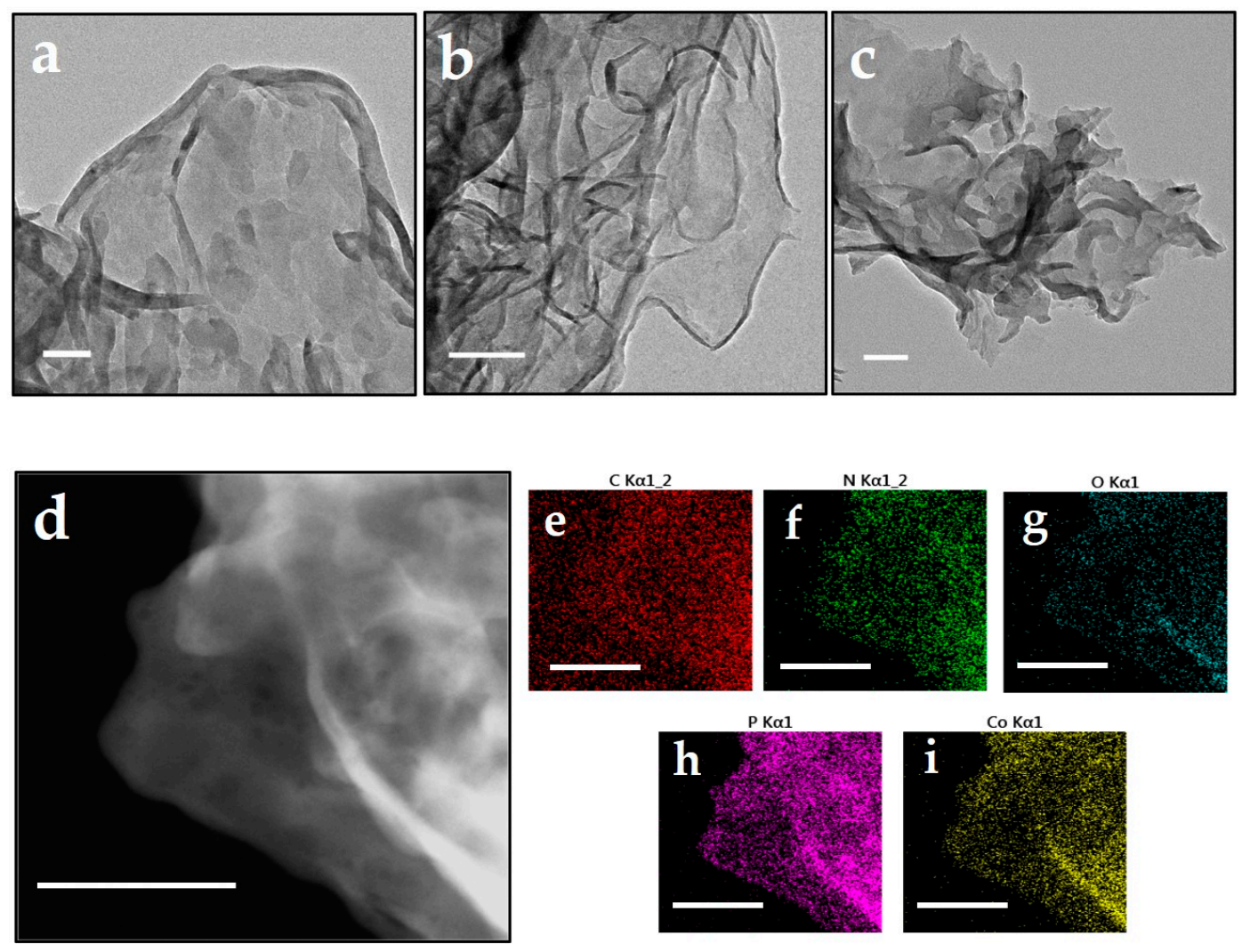

Figure 2. TEM images of (a) CN, (b) PCN, (c) Co@PCN (scale bar: $100 \mathrm{~nm}$ ), and (d-i) scanning transmission electron microscope (STEM) images of Co@PCN and the EDX elemental mapping analysis (scale bar: $150 \mathrm{~nm}$ ).

The X-ray photoelectron spectroscopy (XPS) analysis images of CN, PCN, and Co@PCN are given in Figure 3, and the atomic percentages of these particles are listed in Table 1. In the $\mathrm{C} 1 \mathrm{~s}$ spectrum (Figure $3 \mathrm{~b}$ ) of $\mathrm{CN}$, the peaks at 285.08 and $288.28 \mathrm{eV}$ were attributed to the $\mathrm{sp}^{2}$ graphitic carbon $(\mathrm{C}-\mathrm{C}=\mathrm{C})$ and $\mathrm{sp}^{2}$-bonded carbon in the triazine rings $(\mathrm{N}-\mathrm{C}=\mathrm{N})$, respectively [43]. CN has a lower area ratio of graphitic carbon than PCN, and C-O $(289.48 \mathrm{eV})$ appeared. The C 1s XPS spectra of Co@PCN can be divided into four peaks at 284.93, $287.23,288.13$, and $288.78 \mathrm{eV}$, corresponding to $\mathrm{sp}^{2}$ graphitic $\mathrm{C}, \mathrm{C}-\mathrm{N}, \mathrm{sp}^{2}$-bonded carbon in $\mathrm{N}-\mathrm{C}=\mathrm{N}$, and $\mathrm{sp}^{2}$-hybridized $\mathrm{C}$ bonded to $-\mathrm{NH}_{2}$ on the aromatic ring, respectively [22]. The XPS N 1s spectra of CN (Figure 3c) at 398.68, 399.28, and $400.68 \mathrm{eV}$ were attributed to $\mathrm{sp}^{2}$-hybridized nitrogen $\mathrm{C}-\mathrm{N}=\mathrm{C}$, tertiary nitrogen $\mathrm{N}-\mathrm{C} 3$, and $\mathrm{C}-\mathrm{N}-\mathrm{H}$ (positive charge localization in heterocycles), respectively [35]. The last peak positioned at $401.78 \mathrm{eV}$ was identified as $\mathrm{C}-\mathrm{NH}_{2}$ in PCN [44,45]. Two additional peaks for Co@PCN located at 398.98 and $400.48 \mathrm{eV}$ corresponded to $\mathrm{N}-\mathrm{Co}$ and $\mathrm{C}-\mathrm{NH}_{2}$, respectively [34,46]. The $\mathrm{C} 1 \mathrm{~s}$ XPS spectra of PCN and Co@PCN (Figure 3d) can be divided into two peaks at $531.43 \mathrm{eV}$ and $532.88 \mathrm{eV}$, corresponding to adsorbed $\mathrm{O}$ and oxygen and $\mathrm{H}_{2} \mathrm{O}$ on the surface [22]. The $\mathrm{P} 2 \mathrm{p}$ XPS spectra of PCN and Co@PCN contained peaks at 133.13, 133.93, and $134.83 \mathrm{eV}$, which correspond to $\mathrm{P}-\mathrm{N}, \mathrm{P}=\mathrm{N}$, and $\mathrm{P}-\mathrm{O}$ bonds, respectively (Figure $3 \mathrm{e})[36,39,47]$. This implied that $\mathrm{P}$ likely replaced $\mathrm{C}$ in the $s$-triazine units to form $\mathrm{P}-\mathrm{N}$ and $\mathrm{P}=\mathrm{N}$ bonds because the binding energies of $\mathrm{P}-\mathrm{C}$ coordination bonds $(131.2-132.2 \mathrm{eV})$ were lower than that of $\mathrm{P}-\mathrm{N}$ and $\mathrm{P}=\mathrm{N}$ bonds [22]. $\mathrm{P}-\mathrm{O}$ bonds were ascribed to oxidized $\mathrm{P}$ on the surface [39]. The Co $2 \mathrm{p}$ spectrum is displayed in Figure $3 \mathrm{f}$, and the peaks positioned at 781.43 and $797.63 \mathrm{eV}$ were 
associated with $\mathrm{Co}^{3+}$. The peaks at 783.03 and $801.48 \mathrm{eV}$ were related to $\mathrm{Co}^{2+}[48,49]$. The peaks at 803.98 and $786.48 \mathrm{eV}$ were assigned to the satellite peaks of $\mathrm{Co} 2 \mathrm{p}_{1 / 2}$ and $2 \mathrm{p}_{3 / 2}$ [49]. The peaks at 779.6 and $795.0 \mathrm{eV}$ were related to the $\mathrm{Co}-\mathrm{N}_{\mathrm{x}}$ structure of $\mathrm{Co} @ \mathrm{PCN}$, which formed due to van der Waals forces [50,51].
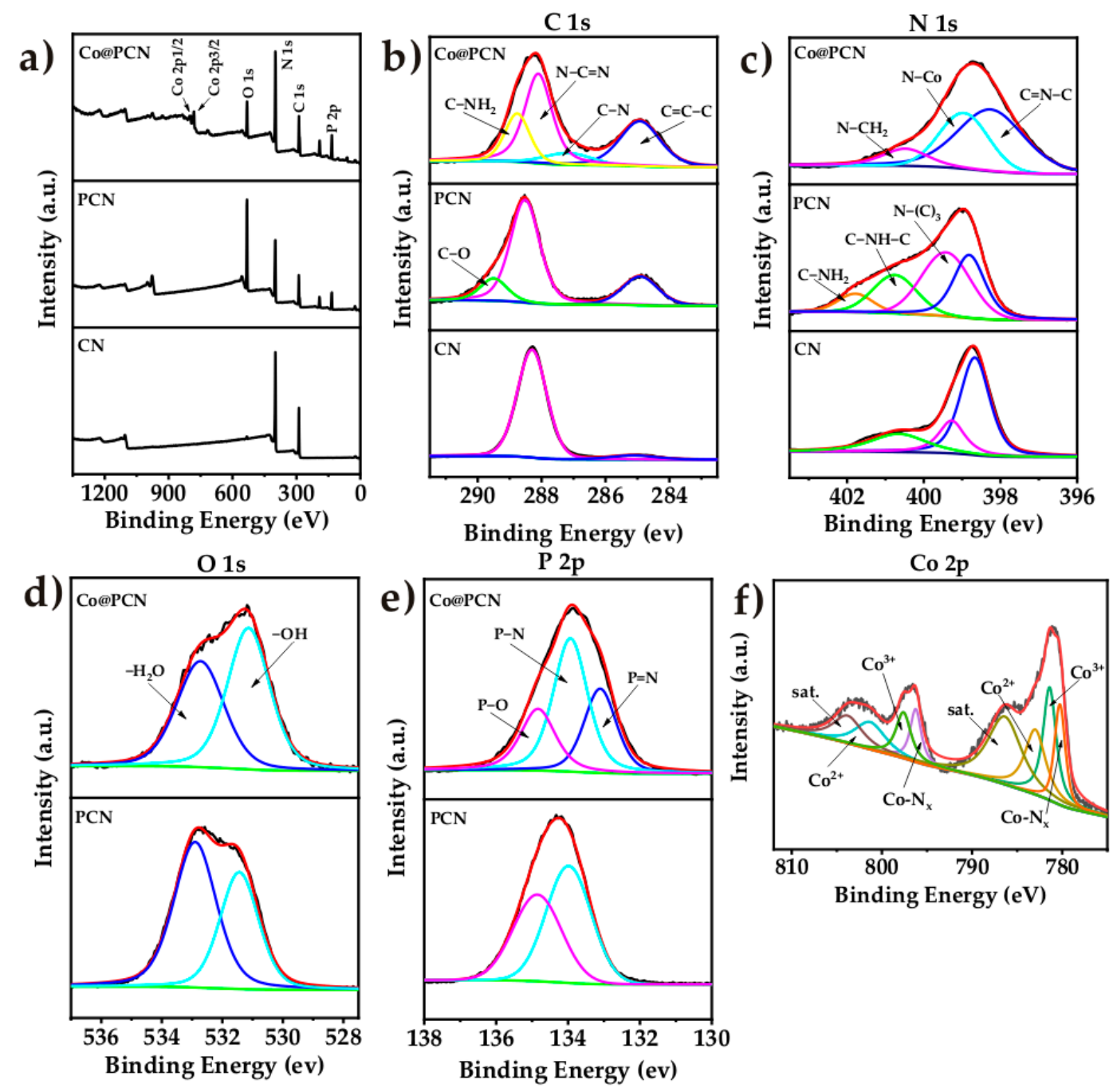

Figure 3. (a) XPS survey spectrum and high-resolution XPS spectra of (b) C 1s, (c) N 1s, (d) O 1s, (e) P 2p, and (f) Co 2p core levels in flame-retardant particles.

Table 1. The C, N, O, P, and Co atomic percentage of $\mathrm{CN}, \mathrm{PCN}$, and $\mathrm{Co} / \mathrm{PCN}$.

\begin{tabular}{cccccc}
\hline Samples & C, at.\% & N, at.\% & O, at.\% & P, at.\% & Co, at.\% \\
\hline CN & 41.74 & 56.93 & 1.33 & - & - \\
PCN & 25.90 & 33.30 & 32.54 & 8.14 & - \\
Co@PCN & 32.20 & 43.52 & 11.45 & 10.05 & 2.78 \\
\hline
\end{tabular}

The thermogravimetric analysis (TGA) curves of CN, PCN, and Co@PCN are shown in Figure 4 (in nitrogen), and the corresponding thermal decomposition data are given in Table 2. The initial decomposition temperature, the temperature at $50 \%$ weight loss, and the temperature at the maximal weight were recorded as $\mathrm{T}_{-5}, \mathrm{~T}_{-50}$, and $\mathrm{T}_{-\max }$, respectively. $\mathrm{CN}$ presented a one-step decomposition process over the whole temperature range. Unlike $\mathrm{CN}, \mathrm{PCN}$ exhibited three different thermal decomposition processes (Figure $4 \mathrm{~b}$ ). The decomposition of $\mathrm{PCN}$ at $200-550{ }^{\circ} \mathrm{C}$ may be attributed to the decomposition of a small amount of oxidized P and oligomers. The $\mathrm{T}_{-50}$ of PCN and $\mathrm{Co} @ \mathrm{PCN}$ were higher than 
that of $\mathrm{CN}$, indicating that the formation of a graphitic polyheptanazine framework was not affected by phosphorus doping or cobalt loading. The residues of PCN and Co@PCN at $750{ }^{\circ} \mathrm{C}$ were $26.3 \%$ and $47.1 \%$, respectively, which were much higher than that of $\mathrm{CN}$, typically $0 \%$ at $750{ }^{\circ} \mathrm{C}$. This indicated that phosphorus doping greatly increased the residues of $\mathrm{CN}$, possibly due to the formation of $\mathrm{P}-\mathrm{N}$ bonds, which encouraged the retention of $\mathrm{P}$ in the condensed phase during thermal decomposition.
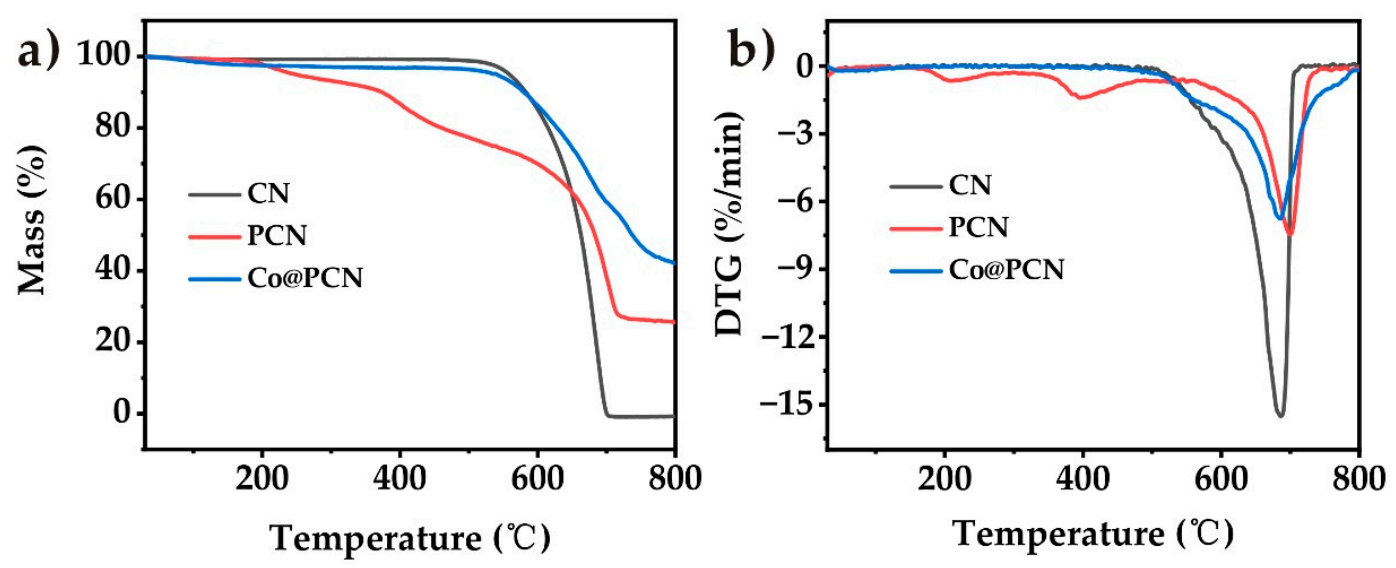

Figure 4. (a) TG and (b) DTG curves of three kinds of flame retardants in nitrogen atmosphere.

Table 2. The related data of three kinds of flame retardants in nitrogen atmosphere.

\begin{tabular}{ccccc}
\hline Sample & $\mathbf{T}_{-\mathbf{5}} \mathbf{1}$ & $\mathbf{T}_{-\mathbf{5 0}}{ }^{2}$ & $\mathbf{T}_{-\max }{ }^{3}$ & Residues at $\mathbf{7 5 0}{ }^{\circ} \mathbf{C}(\mathbf{w t} \mathbf{\%})$ \\
\hline $\mathrm{CN}$ & 558 & 663 & 686 & 0 \\
$\mathrm{PCN}$ & 247 & 683 & 699 & 26.3 \\
$\mathrm{Co@PCN}$ & 541 & 738 & 685 & 47.1 \\
\hline
\end{tabular}

${ }^{1} \mathrm{~T}_{-5}$ corresponds to the temperature at $10 \%$ weight loss. ${ }^{2} \mathrm{~T}_{-50}$ corresponds to the temperature at $50 \%$ weight loss. ${ }^{3} \mathrm{~T}_{-\max }$ corresponds to the temperature at maximal weight loss rate.

\subsection{Fracture Surface Analysis of TPU and its Nanocomposites}

Dispersions of CN, PCN, and Co@PCN with the TPU matrix were studied using SEM. From Figure 5a, pure TPU had a relatively smooth and fractured surface while the fracture surfaces of CN-TPU, PCN-TPU, and Co@PCN-TPU were rough and uneven. CN particles were tightly embedded in TPU (Figure 5b), demonstrating their strong interactions with the polymer. As shown in Figure 5c, aggregations were observed in PCN-TPU, suggesting the poor dispersion of PCN particles in the TPU matrix. For Co@PCN-TPU (Figure 5d), the aggregates dispersed in the TPU matrix were larger than those in PCN-TPU. This may lead to poor flame retardancy test performance. SEM images of the fracture surface of PCN-TPU and Co@PCN-TPU at different rotating speeds were also investigated (Figures S1 and S2). It can be concluded that changing the rotational speed has a limited effect on improving the dispersion of flame-retardant additives. CN particles were well-dispersed, as shown by analysis of the fracture surface of TPU and its nanocomposites. However, the condensed-phase flame retardancy mechanism of $\mathrm{CN}$ did not promote the formation of residues and the flame retardancy effect was still much lower than that of PCN and Co@PCN. 

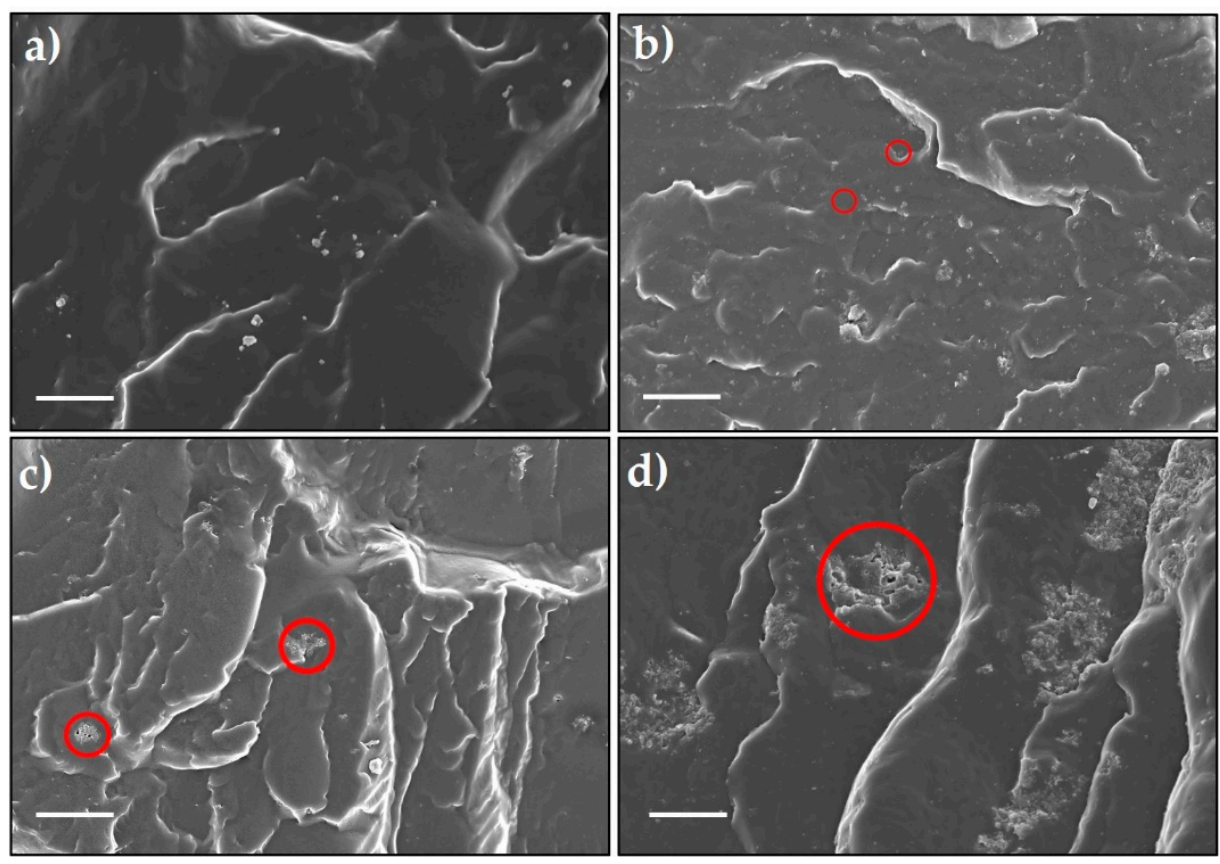

Figure 5. SEM images of the fracture surface of (a) Pure thermoplastic polyurethane (TPU), (b) CNTPU, (c) PCN-TPU, and (d) Co@PCN-TPU (scale bar: $15 \mu \mathrm{m}$ ).

\subsection{Thermal Stability and Fire Resistance of TPU and Its Composites}

The thermal decomposition of the TPU composites in nitrogen is shown in Figure 6, and the corresponding parameters are listed in Table 3. All nanocomposites exhibited similar degradation behavior to that of pure TPU (Figure 6). $\mathrm{T}_{-5}$ of CN-TPU decreased slightly after the introduction of $\mathrm{CN}$, while $\mathrm{T}_{-5}$ of PCN-TPU was $19^{\circ} \mathrm{C}$ lower than that of pure TPU, which may be attributed to the presence of a small amount of oxidized $\mathrm{P}$ in PCN. The initial decomposition temperature of Co@PCN-TPU was $4{ }^{\circ} \mathrm{C}$ higher than that of pure TPU, which was due to the higher thermal stability of Co@PCN. T -50 of CN-TPU and PCN-TPU were basically the same as that of pure TPU, while $\mathrm{T}_{-50}$ of Co@PCN-TPU was $10{ }^{\circ} \mathrm{C}$ higher than that of pure TPU. The residues of CN-TPU, PCN-TPU, and Co@PCNTPU at $700{ }^{\circ} \mathrm{C}$ were $5.2,9.5$, and $10.7 \%$, respectively, which were $4.4 \%$ higher than pure TPU. This phenomenon demonstrated that the introduction of phosphorus increased the residues, which was attributed to the effect of $\mathrm{P}-\mathrm{N}$ bonds [12]. The overall influence of PCN and Co@PCN was that the incorporated additives did not influence the decomposition of polyurethane bonds but slightly increased the residue percentage formed during the decomposition of polyols (the second decomposition step in Figure 5b).
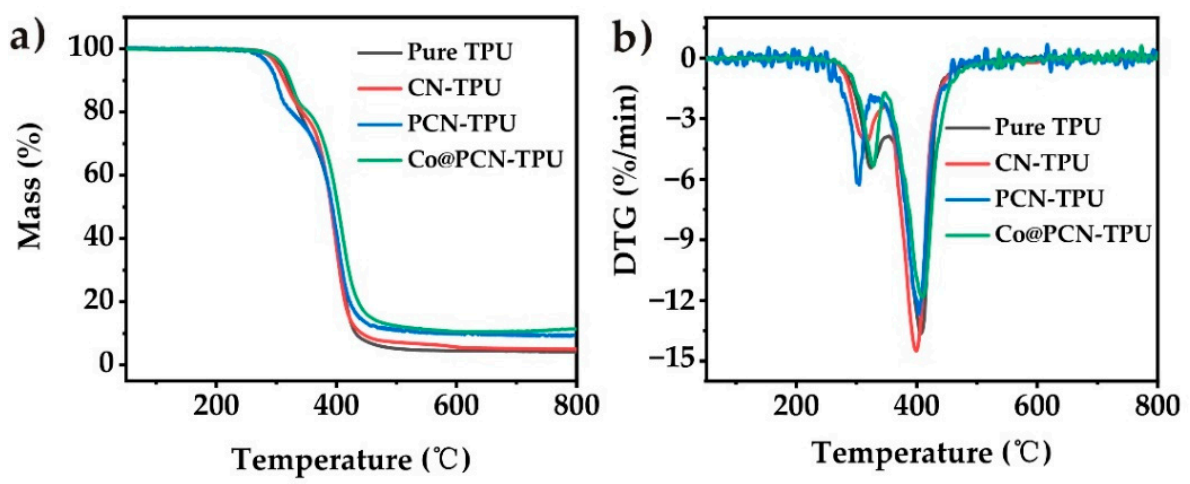

Figure 6. (a) TG and (b) DTG curves of TPU and its composites in nitrogen atmosphere. 
Table 3. The related data of TPU and its composites in nitrogen atmosphere.

\begin{tabular}{ccccc}
\hline Sample & $\mathbf{T}_{-\mathbf{5}}$ & $\mathbf{T}_{-\mathbf{5 0}}$ & $\mathbf{T}_{-\max }$ & Residues at $\left.\mathbf{7 0 0}{ }^{\circ} \mathbf{C} \mathbf{( w t} \%\right)$ \\
\hline Pure TPU & 306 & 392 & 407 & 4.4 \\
CN-TPU & 300 & 391 & 399 & 5.2 \\
PCN-TPU & 287 & 393 & 404 & 9.5 \\
Co@PCN-TPU & 310 & 402 & 410 & 10.7 \\
\hline
\end{tabular}

The flame retardancy of TPU and its nanocomposites under nitrogen atmosphere was evaluated by microcalorimetry (MCC). As shown in Figure 7 and Table 4, the peak heat release rate (pHRR) and total heat release (THR) of pure TPU during combustion were $407.8 \mathrm{~kW} / \mathrm{m}^{2}$ and $86.34 \mathrm{MJ} / \mathrm{m}^{2}$, respectively. The pHRR for PCN-TPU was $33.8 \%$ lower while the pHRR of Co@PCN-TPU decreased by $16.4 \%$ compared with pure TPU. It can be seen that $\mathrm{CN}$ has a good thermal inhibition effect in a nitrogen atmosphere. Figure 7b shows that the incorporation of PCN and Co@PCN further reduced the THR of the nanocomposites. It demonstrated that the introduction of phosphorus or cobalt is beneficial to further reduce the THR of nanocomposites under nitrogen atmosphere.
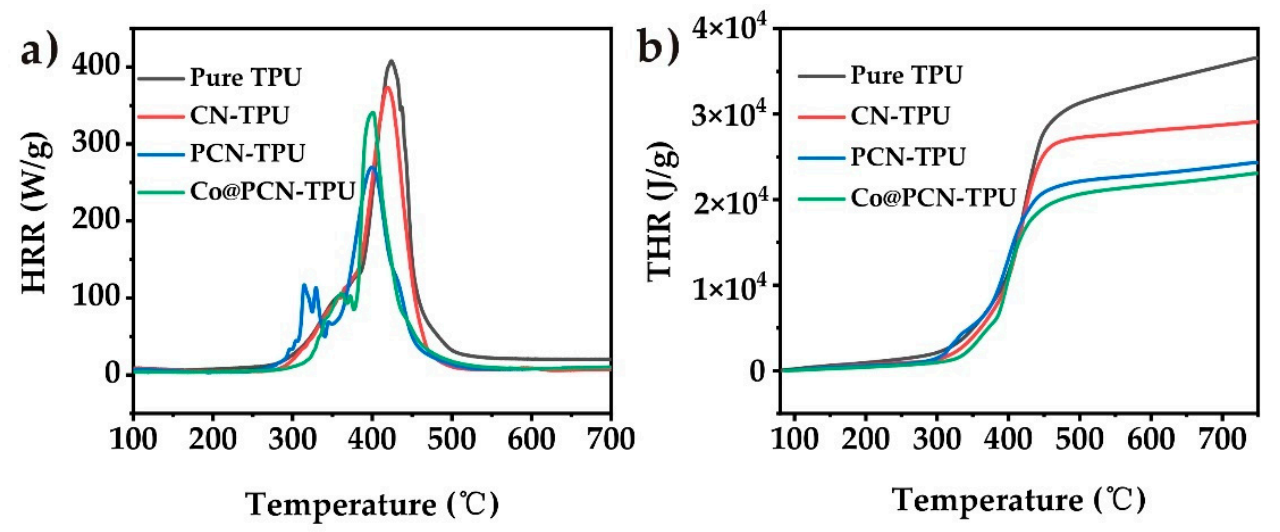

Figure 7. (a) Heat release rate and (b) total heat release curves of TPU and its nanocomposites obtained from microcalorimetry (MCC).

Table 4. Combustion parameters of TPU and its nanocomposites obtained from MCC and CCT.

\begin{tabular}{|c|c|c|c|c|c|}
\hline Sample & $\begin{array}{c}\mathrm{pHRR}^{1} \\
(\mathrm{~W} / \mathrm{g})\end{array}$ & $\begin{array}{c}\mathrm{pHRR}^{2} \\
(\mathrm{~W} / \mathrm{g})\end{array}$ & $\begin{array}{c}\text { THR } \\
\left(\mathrm{MJ} / \mathrm{m}^{2}\right)\end{array}$ & $\operatorname{pSPR}\left(\mathrm{m}^{2} / \mathrm{s}\right)$ & Residues (\%) \\
\hline Pure TPU & 407.8 & 509.4 & 86.34 & 0.0847 & 10.18 \\
\hline CN-TPU & 373.2 & 561.4 & 82.31 & 0.0985 & 7.25 \\
\hline PCN-TPU & 269.9 & 262.2 & 74.01 & 0.0631 & 17.04 \\
\hline Co@PCN-TPU & 341.0 & 305.4 & 76.68 & 0.0662 & 14.08 \\
\hline
\end{tabular}

${ }_{1}^{1}$ pHRR corresponded to the peak heat release rate measured by MCC. ${ }^{2}$ pHRR corresponded to the peak heat release rate measured by CCT.

The HRR and THR curves obtained from cone calorimetry tests (CCT) of pure TPU and its nanocomposites are shown in Figure 8 . The pHRR of pure TPU was $509.4 \mathrm{~kW} / \mathrm{m}^{2}$ while that of CN-TPU was $561.4 \mathrm{~kW} / \mathrm{m}^{2}$, which was the highest of all samples (Figure 8a). It demonstrated that the addition of untreated $\mathrm{CN}$ alone did not help reduce the $\mathrm{pHRR}$ of thermoplastic polyurethane. After the introduction of PCN and Co@PCN into the polymer, the pHRR decreased by $48.5 \%$ and $40.1 \%$ for PCN-TPU and Co@PCN-TPU, respectively, rivaled by pure TPU. PCN and Co@PCN changed the pyrolysis process of TPU, forming more char layers, which was mainly attributed to the formation of $\mathrm{P}-\mathrm{N}$ bonds and $\mathrm{P}=\mathrm{N}$ bonds in triazine rings, which promoted the retention of $\mathrm{P}$ in the condensed phase and produced more high-quality residues. 

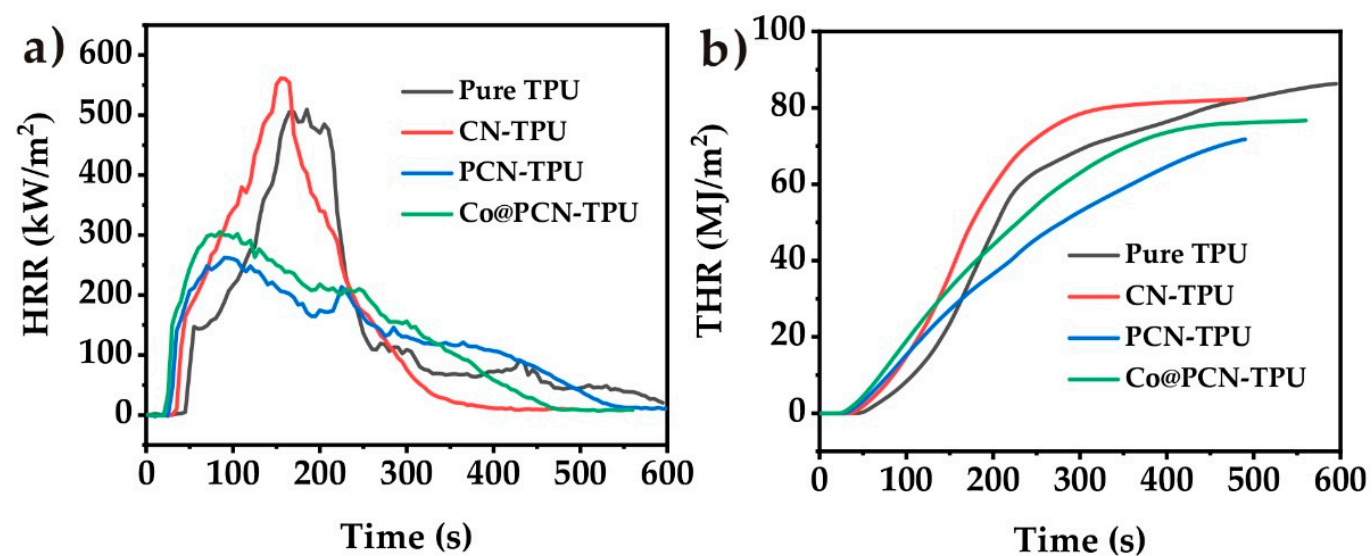

Time (s)
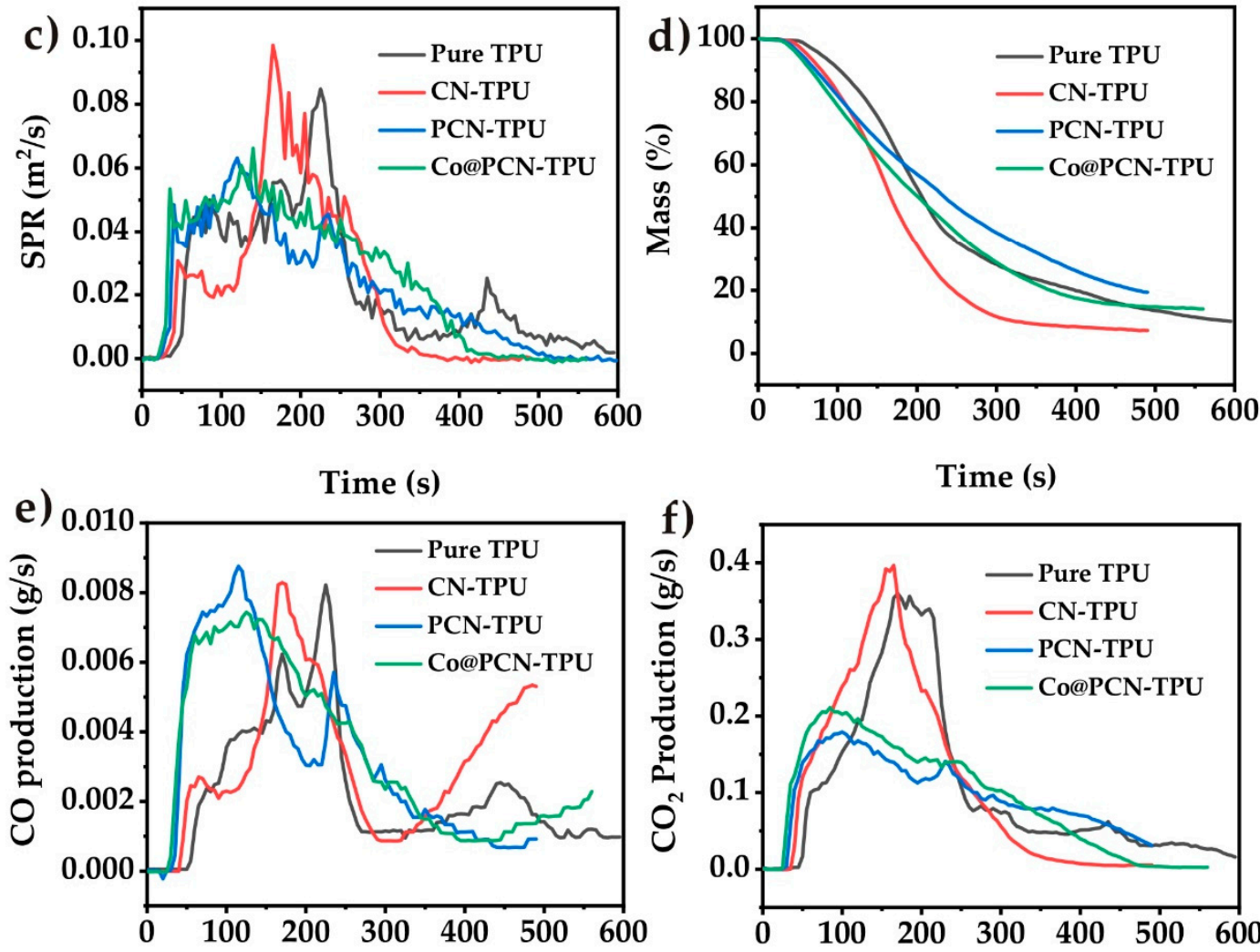

Time (s)

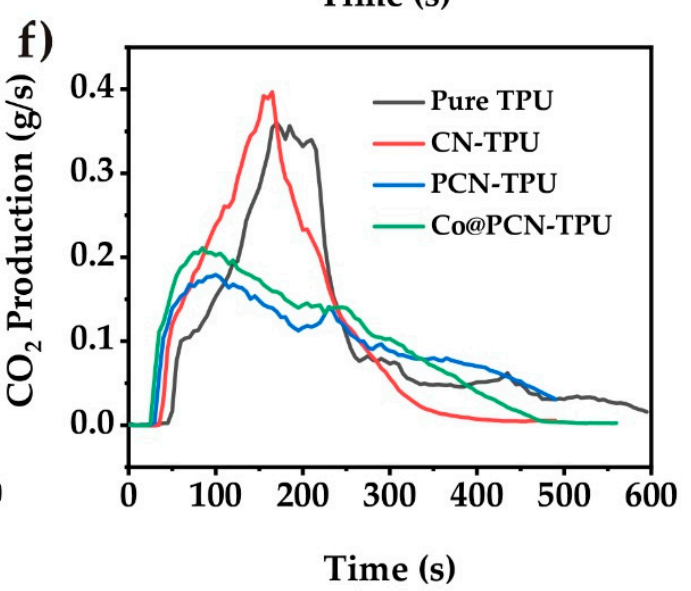

Figure 8. (a) Heat release rate (HRR), (b) total heat release (THR), (c) smoke-production rate (SPR), (d) mass, (e) CO, and (f) $\mathrm{CO}_{2}$ curves of TPU and its nanocomposites obtained from cone calorimetry tests (CCTs).

The results in Figure 8b show that PCN-TPU and Co@PCN-TPU degraded slightly earlier than pure TPU samples. The THR of pure TPU, CN-TPU, PCN-TPU, and Co@PCN-TPU were $86.34 \mathrm{MJ} / \mathrm{m}^{2}, 82.31 \mathrm{MJ} / \mathrm{m}^{2}, 74.01 \mathrm{MJ} / \mathrm{m}^{2}$, and $76.68 \mathrm{MJ} / \mathrm{m}^{2}$, respectively (Table 4). PCN and Co@PCN encouraged the production of more residues and reduced the mass loss, thus reducing the value of total heat release. The CCT results showed that the flame-retardant efficiency of PCN was better than that of Co@PCN.

The smoke-production rate (SPR) curves of pure TPU and its composites are shown in Figure 8c. The pSPR was greatly reduced after the introduction of PCN and Co@PCN, indicating that smoke toxicity of TPU decreased. Under the same filling contents, PCN-TPU presented the lowest pSPR and showed the best smoke-suppression performance of all samples. This was attributed to the charring ability of the condensed phase of modified polyheptanazine, which reduced heat release and smoke production. 
Figure $8 \mathrm{~d}$ gives the mass loss curves of nanocomposites as a function of time. The lower mass loss was ascribed to the formation of a high-quality char on the nanocomposite surface and its structure improvement [52]. Only $10.18 \%$ of pure TPU remained after the CCT test. The PCN-TPU plot shows a high residue value of $17.04 \%$, which indicates that P-doped polyheptanazine was cross-linked. Moreover, the char residues formed on the surface can prevent heat and mass transfer, further reducing mass loss and improving fire safety.

It has been reported that the char residues of cyclo-P-N bond composites include $\mathrm{P}-\mathrm{O}-\mathrm{P}$ bonds and $\mathrm{P}-\mathrm{O}-\mathrm{C}$ bonds $[53,54]$. Combined with the TG data, it can be inferred that the increase of residues during cone calorimetry tests may be attributed to the production of phosphoric acid or polyphosphate during pyrolysis, which promotes the formation of heat-resistant carbonaceous compounds.

The curves of $\mathrm{CO}$ and $\mathrm{CO}_{2}$ evolution as a function of time obtained from CCT are shown in Figure 8e,f, and the total amount of $\mathrm{CO}$ and $\mathrm{CO}_{2}$, and the corresponding $\mathrm{CO}_{2} / \mathrm{CO}$ ratio of TPU and its nanocomposites after complete combustion are listed in Table 5. CO and $\mathrm{CO}_{2}$ are the main components of fire gas. A high concentration of $\mathrm{CO}$ will lead to carbon monoxide poisoning due to obstruction of escape in a fire. The lower values of $\mathrm{CO}_{2} / \mathrm{CO}$ ratio indicated that the low efficiency of combustion and the conversion of $\mathrm{CO}$ to $\mathrm{CO}_{2}$ are inhibited [55]. As shown in Table 5, the yields of CO of PCN-TPU and Co@PCNTPU were higher than that of pure TPU, but PCN-TPU and Co@PCN-TPU had lower yields of $\mathrm{CO}_{2}$ compared to pure TPU, leading to a decrease in $\mathrm{CO}_{2} / \mathrm{CO}$ ratios (29.7 and 27.8 vs. 44.9). This may be due to the reaction between a small amount of oxidized $P$ with the polymer matrix, which prevents further oxidation of $\mathrm{CO}$ release from PCN-TPU and Co@PCN-TPU in the first combustion process into $\mathrm{CO}_{2}$, whereas that reaction could not occur in the combustion process of pure TPU.

Table 5. $\mathrm{CO}_{2}$ and CO data, and UL-94 test results of TPU and its nanocomposites.

\begin{tabular}{ccccc}
\hline Sample & $\left.\mathbf{C O}_{\mathbf{2}} \mathbf{( k g} / \mathbf{k g}\right)$ & $\mathbf{C O}(\mathbf{k g} / \mathbf{k g})$ & $\mathbf{C O}_{\mathbf{2}} / \mathbf{C O}$ & $\mathrm{UL}-94$ \\
\hline Pure TPU & 61.0 & 1.36 & 44.9 & $\mathrm{~V}-2$ \\
CN-TPU & 56.9 & 1.53 & 37.2 & $\mathrm{~V}-2$ \\
PCN-TPU & 48.4 & 1.63 & 29.7 & $\mathrm{~V}-2$ \\
Co@PCN-TPU & 51.4 & 1.85 & 27.8 & $\mathrm{~V}-2$ \\
\hline
\end{tabular}

TPU and its nanocomposites passed the UL-94 V-2 rating with melt dripping in the vertical burning test. Furthermore, the dripping object ignited the absorbent cotton. $\mathrm{t} 1+\mathrm{t} 2$ (Total burning time is used to evaluate the UL-94 rating.) in the UL-94 test decreased as the flame retardants were incorporated. $\mathrm{t} 1+\mathrm{t} 2$ of pure TPU is $3 \mathrm{~s}$ while those of PCN-TPU and Co@PCN-TPU are shorter.

To highlight the improved fire performance of phosphorus-doped polyheptanazine in the TPU matrix, the performance of PCN-TPU was compared with the reported results of other flame-retardant TPU nanocomposites (Table 6). It can be inferred that PCN encourages the formation of char residues, resulting in decreased pHRR values. Table 6 also shows that PCN has a definite smoke-suppression effect. In this work, the introduction of PCN to TPU remarkably reduced the PHRR (48.5\%), which was better than most reported results. Yang et al. [56] fabricated cetyltrimethylammonium bromide (CTAB)-modified $\mathrm{Ti}_{3} \mathrm{C}_{2}$ (MXene) ultra-thin nanosheets $\left(\mathrm{CTAB}-\mathrm{Ti}_{3} \mathrm{C}_{2}\right.$ ). Despite excellent flame retardance properties ( $-51.2 \%$ in $\mathrm{pHRR})$, the use of MXene flame retardants has been greatly limited because their preparation methods are expensive and difficult to industrialize. The raw materials used in this paper are urea and diammonium hydrogen phosphate, which are produced industrially, making them easy to acquire. In addition, the preparation method of PCN is simple. 
Table 6. Thermal and burning parameters of TPU flame-retardant composites reported in previous work and this work.

\begin{tabular}{ccccc}
\hline Recipes & Residues $(\mathbf{w t} \%)^{\mathbf{1}}$ & pHRR & pSRR & Year and Ref. \\
\hline $2 \mathrm{wt} \% \mathrm{CTAB}-\mathrm{Ti}_{3} \mathrm{C}_{2}$ & $1.3 \rightarrow 6.1$ & $-51.2 \%$ & $-57.1 \%$ & $2019[56]$ \\
$3 \mathrm{wt} \% \mathrm{CPBN}$ & $4.1 \rightarrow 10.2$ & $-35.6 \%$ & - & $2019[57]$ \\
$2 \mathrm{w} \mathrm{t} \% \mathrm{CeO}_{2} / \mathrm{rGO}$ & $7.3 \rightarrow 9.7$ & $-41.1 \%$ & $-50.0 \%$ & $2019[58]$ \\
$2 \mathrm{wt} \% \mathrm{CSACS} \mathrm{C}$ & $0.3 \rightarrow 2.0$ & $-35.9 \%$ & - & $2019[59]$ \\
$2 \mathrm{wt} \% \mathrm{Co}_{3} \mathrm{O}_{4}-\mathrm{GNS}$ & $2.8 \rightarrow 8.5$ & $-16.4 \%$ & - & $2016[32]$ \\
$1.5 \mathrm{wt} \% \mathrm{rGO}-\mathrm{Salen}-\mathrm{Ni}$ & $5.5 \rightarrow 9.0$ & $-43.1 \%$ & - & $2018[60]$ \\
$3 \mathrm{wt} \% \mathrm{HC}-\mathrm{Mo}$ & $3.4 \rightarrow 6.6$ & $-38.3 \%$ & $-32.1 \%$ & $2018[61]$ \\
$3 \mathrm{wt} \% \mathrm{PCN}$ (This work) & $4.4 \rightarrow 9.5$ & $-48.5 \%$ & $-25.5 \%$ & This work \\
\hline
\end{tabular}

${ }^{1}$ Residues corresponded to the change of residual quantity.

\subsection{Evolution of Pyrolysis Gas}

Simultaneous thermal analysis coupled with Fourier-transform infrared spectrometry (TG-IR) was used to detect the effect of those particles on the pyrolysis behavior of pure TPU, CN-TPU, PCN-TPU, and Co@PCN-TPU (Figure 9). TPU nanocomposites showed similar main spectra bands to that of pure TPU, and those bands were attributed to functional groups or components with characteristic band positions (Figure 10), including $\mathrm{CO}_{2}$ $\left(2358 \mathrm{~cm}^{-1}\right)$, aromatic compounds $\left(1508\right.$ and $\left.1460 \mathrm{~cm}^{-1}\right)$, esters $\left(1145 \mathrm{~cm}^{-1}\right)$, hydrocarbons (2977 and $\left.2880 \mathrm{~cm}^{-1}\right)$, carbonyl compounds $\left(1751 \mathrm{~cm}^{-1}\right)$, and $\operatorname{HCN}\left(714 \mathrm{~cm}^{-1}\right)[57,62,63]$. The results showed that pure TPU and CN-TPU exhibited similar thermal decomposition processes while PCN-TPU decomposed slightly earlier. This demonstrated that incorporating these flame-retardant particles into TPU may not change the primary decomposition process.
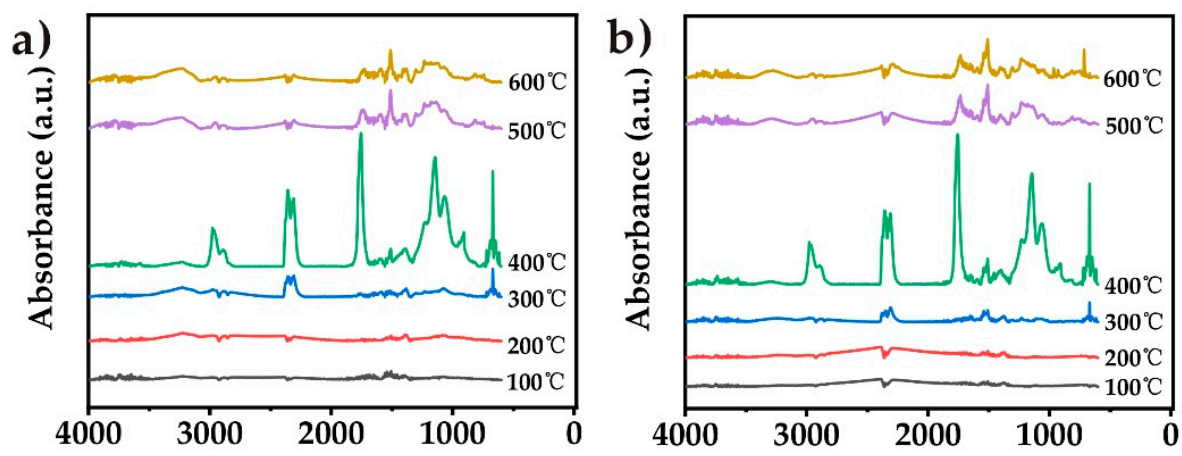

Wavenumber $\left(\mathrm{cm}^{-1}\right)$

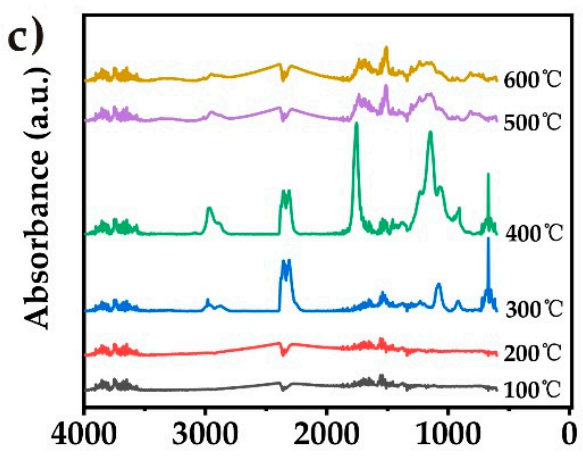

Wavenumber $\left(\mathrm{cm}^{-1}\right)$

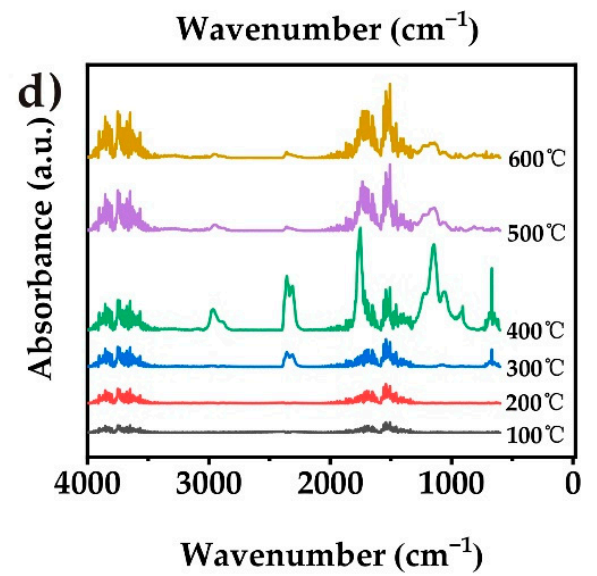

Figure 9. IR spectra of pyrolysis products for the samples at different stages of decomposition: (a) pure TPU, (b) CN-TPU, (c) PCN-TPU, and (d) Co@PCN-TPU. 

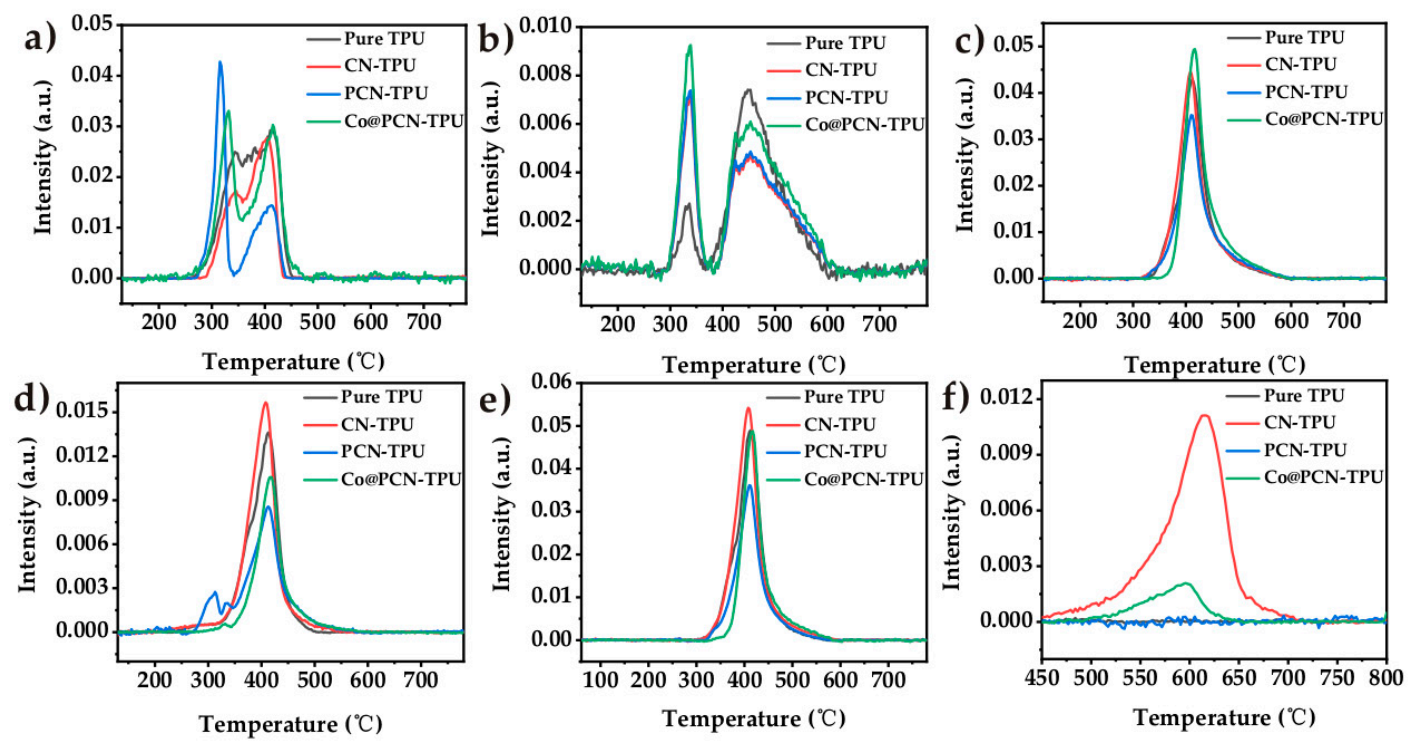

Figure 10. Intensities of characteristic peaks for pyrolysis gaseous products of TPU and its nanocomposites: (a) $2358 \mathrm{~cm}^{-1}$, (b) $1508 \mathrm{~cm}^{-1}$, (c) $1145 \mathrm{~cm}^{-1}$, (d) $2977 \mathrm{~cm}^{-1}$, (e) $1751 \mathrm{~cm}^{-1}$, and (f) $714 \mathrm{~cm}^{-1}$.

Figure 10a shows that the decomposition of PCN-TPU released abundant $\mathrm{CO}_{2}$ during the first stage, which was related to the slightly earlier decomposition due to the addition of PCN during TGA (Figure 6) and MCC (Figure 7). This can enhance the gas-phase flame-retardant mechanism of the nanocomposites. The inhibition of PCN-TPU was better than that of Co@ PCN-TPU in the remaining characteristic band analysis. This can be attributed to the better char-formation ability of PCN in the matrix. Figure $10 \mathrm{~b}$ shows the evolution trend of aromatic compounds. The addition of three fillers increased the intensity of the first stage and decreased the intensity of the second stage, which did not prolong the ignition time of the nanocomposite during CCT. This is different from the previous literature that stated Co compounds can inhibit the formation of aromatic compounds [31]. In addition, PCN-TPU showed a different phenomenon from other samples in the hydrocarbon curve in Figure 10d. A few hydrocarbons were released during the first stage, which may be attributed to the reaction of a small amount of oxidized $\mathrm{P}$ with the polymer matrix, corresponding to premature decomposition of PCN-TPU in TGA. Figure 10f shows that PCN changed the decomposition pathway, thus avoiding $\mathrm{HCN}$ produced by polyheptanazine decomposition. This stage corresponds to the $500-600{ }^{\circ} \mathrm{C}$ decomposition stage in TGA.

\section{Materials and Methods}

\subsection{Materials}

TPU (S80A, BASF SE) with a density of $1.21 \mathrm{~g} / \mathrm{cm}^{3}$, urea $(99 \%$, J\&K Scientific, Ltd., Beijing, China), diammonium hydrogen phosphate (99\%, Shanghai Macklin Biochemical Co., Ltd., Shanghai, China), Cobalt (II) acetate tetrahydrate (99.5\%, Shanghai Macklin Biochemical Co., Ltd.), and ethanol ( $\geq 99.7 \%$, Shanghai Titan Scientific Co., Ltd., Shanghai, China) were used as received without further purification.

\subsection{Preparation of Phosphorus-Doped Polyheptazine Nanomaterials (PCN)}

A preparation scheme of PCN and Co@PCN is shown in Scheme 1. PCN were synthesized by the thermal-condensation method using diammonium hydrogen phosphate as the P source and urea as the polyheptazine precursor. In detail, $40 \mathrm{~g}$ of urea and $2.4 \mathrm{~g}$ of diammonium hydrogen phosphate were thoroughly mixed, and the resulting mixture was placed in an open porcelain crucible. The crucible was placed in a muffle furnace (KSL-1200X, Hefei Ke Jing Materials Technology Co., Ltd., Hefei, China) and calcined at $550{ }^{\circ} \mathrm{C}$ for $2 \mathrm{~h}$ with a heating rate of $5{ }^{\circ} \mathrm{C} \mathrm{min}^{-1}$. The obtained yellow product was crushed 
with a grinder into fine grains for further use. In the absence of diammonium hydrogen phosphate, $\mathrm{CN}$ was synthesized by urea using the same steps.

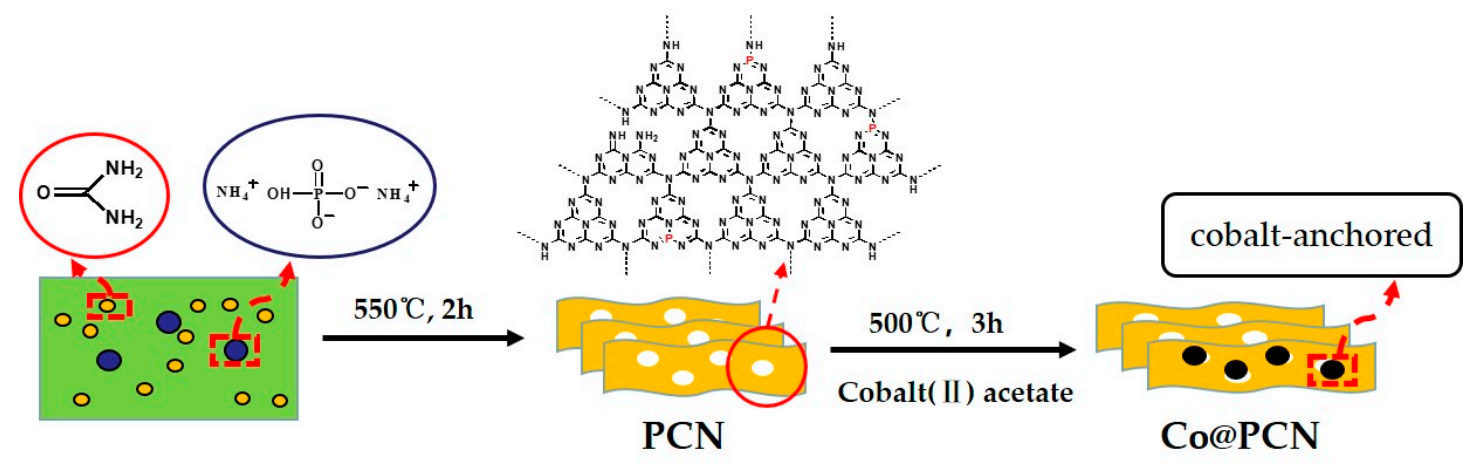

Scheme 1. The used synthetic routes of PCN and Co@PCN.

\subsection{Preparation of Co@PCN Nanomaterials}

Cobalt (II) acetate tetrahydrate $(0.9 \mathrm{~g})$ and $3.6 \mathrm{~g}$ of PCN were dispersed in ethanol, and then, ethanol was evaporated at $50{ }^{\circ} \mathrm{C}$ under magnetic stirring. After drying at $60{ }^{\circ} \mathrm{C}$ for $12 \mathrm{~h}$, the mixture was heated at a rate of $5^{\circ} \mathrm{C} \mathrm{min}-1$ in a muffle furnace from room temperature to $500{ }^{\circ} \mathrm{C}$ and maintained for $3 \mathrm{~h}$. Finally, a wathet blue product was obtained.

\subsection{Preparation of Flame-Retarding TPU}

Pristine TPU and its composites were fabricated by a melt blending method. Typically, $1.5 \mathrm{~g}$ of Co@PCN was blended with $48.5 \mathrm{~g}$ of TPU at $180^{\circ} \mathrm{C}$ in a torque rheometer (RHEOCORD 300P, Germany) for $15 \mathrm{~min}$ with a rotor speed of $80 \mathrm{rpm}$. Next, the sample containing $3.0 \mathrm{wt} \%$ Co@PCN was hot-pressed via a flat vulcanizing machine at $185{ }^{\circ} \mathrm{C}$ to obtain sheets with suitable sizes, which were named TPU/Co@PCN. Other samples with $3.0 \mathrm{wt} \% \mathrm{CN}$ and $3.0 \mathrm{wt} \%$ PCN were labeled CN-TPU and PCN-TPU, respectively. The control sample of pure TPU was also prepared by the same process.

\subsection{Characterization Procedures}

Fourier-transform infrared (FT-IR) spectra were obtained on an FTIR spectrometer (EQUINOX 55, Bruker, Ettlingen, Germany) with scanning from $4000 \mathrm{~cm}^{-1}$ to $400 \mathrm{~cm}^{-1}$.

X-ray diffraction (XRD) patterns were measured by using an X-ray diffractometer (Empyrean, Malvern PANalytical, Almelo, The Netherlands) equipped with $\mathrm{CuK} \alpha$ radiation.

Simultaneous thermogravimetric analysis coupled with differential scanning calorimeter (TG-DSC) was carried out on a simultaneous thermal analyzer (STA449F3/Nicolet6700).

Transmission electron microscopy (TEM) images and energy-dispersive spectroscopy (EDS) analyses were obtained using a FEI Tecnai G2 Spirit instrument with an acceleration voltage of $200 \mathrm{kV}$.

The binding energies of $\mathrm{C}, \mathrm{N}, \mathrm{O}, \mathrm{P}$, and $\mathrm{Co}$ in the samples were determined by $\mathrm{X}$-ray photoelectron spectroscopy (XPS) on a Thermo Fisher Scientific system equipped with Al $\mathrm{K} \alpha$ radiation $(\mathrm{h} v=1486.8 \mathrm{eV})$.

Thermogravimetric analysis (TGA) was carried out on a NETZSCH TG209F1 Libra thermogravimetric analyzer.

The morphology of the prepared composites was investigated by scanning electron microscopy (SEM). The samples were mounted onto an aluminum stub, sputter-coated with gold, and imaged by SEM (Hitachi S-4800 field-emission microscope, Tokyo, Japan) at an accelerating voltage of $10 \mathrm{kV}$. The fracture surface of the flame-retardant samples was prepared by quenching in liquid nitrogen.

Small-scale combustion performance was investigated by a Govmark MCC-2 microcalorimeter (New York, NY, USA). Specifically, $5 \mathrm{mg}$ of samples were heated to $750{ }^{\circ} \mathrm{C}$ with a ramp rate of $1{ }^{\circ} \mathrm{C} / \mathrm{s}$ in a nitrogen stream flowing at $80 \mathrm{~mL} / \mathrm{min}$. The pyrolysis 
products were mixed with oxygen $(20 \mathrm{~mL} / \mathrm{min})$ and then burned in a combustion furnace at $900{ }^{\circ} \mathrm{C}$.

Cone calorimetry tests (CCT) were carried out by an FTT0007 cone calorimeter with $100 \times 100 \times 3.5 \mathrm{~mm}^{3}$. The radiation heat flux was $35 \mathrm{~kW} / \mathrm{m}^{3}$.

UL-94 vertical flame test was measured on a UL94-X type instrument (UL94 Flame Chamber, Motis). The specimens used for the test were of the dimensions $100 \times 13 \times 3.6 \mathrm{~mm}^{3}$.

Simultaneous thermal analysis was interfaced with Fourier-transform infrared spectrometry (TG-IR). The thermal analysis was performed from 30 to $800{ }^{\circ} \mathrm{C}$ with a heating rate of $10{ }^{\circ} \mathrm{C} \mathrm{min}-1$ under a nitrogen atmosphere.

\section{Conclusions}

In this work, PCN and Co@PCN, two functionalized polyheptanazines with enhanced charring, were prepared via thermal condensation and used as flame-retardant fillers for TPU. The results demonstrated that $\mathrm{P}$ replaced $\mathrm{C}$ in the $s$-triazine units to form $\mathrm{P}-\mathrm{N}$ and $\mathrm{P}=\mathrm{N}$ bonds. After ultrasonic treatment of Co@PCN, STEM images showed that Co still had a similar distribution pattern to that of $\mathrm{N}$, indicating that $\mathrm{Co}$ was successfully anchored on the surface of doped polyheptanazine. Cone calorimetry tests showed that PCN-TPU and Co@PCN-TPU remarkably decreased the pHRR, THR, and pSPR compared with pure TPU. In particular, using only $3.0 \mathrm{wt} \%$ filling, the pHRR was decreased by $48.5 \%$ and $40.1 \%$, respectively. The enhanced flame retardancy was mainly attributed to the formation of $\mathrm{P}-\mathrm{N}$ and $\mathrm{P}=\mathrm{N}$ bonds in triazine rings, which promoted the retention of $\mathrm{P}$ in the condensed phase and produced more high-quality residues. The PCN flame retardant suppressed the production of combustible and toxic gases to a certain extent. However, the additional Co anchored on the surface of doped polyheptanazine has no significant effect on the flame retardancy of polymer composites. Furthermore, Co@PCN did not suppress the production of toxic gases such as $\mathrm{CO}$. The effect of in situ introduction of $\mathrm{P}$ and $\mathrm{CO}$ on the charring of polyheptylazine was studied. The results demonstrated that the flame-retardant effect of in situ introduction of $\mathrm{P}$ is better than that of $\mathrm{Co}$. This work may provide a design route to solve the problem whereby nitrogen-containing flame retardants lack a condensed-phase charring effect.

Supplementary Materials: Figure S1: SEM images of fracture surface of $(\mathbf{a}, \mathbf{b})$ PCN-TPU under a rotor speed of $60 \mathrm{rpm}$ and (c,d) PCN-TPU under a rotor speed of $100 \mathrm{rpm}$. Scale bar: $15 \mu \mathrm{m}$, Figure S2: SEM images of fracture surface of $(\mathbf{a}, \mathbf{b})$ Co@PCN-TPU under a rotor speed of $60 \mathrm{rpm}$ and $(\mathbf{c}, \mathbf{d})$ Co@PCN-TPU under a rotor speed of $100 \mathrm{rpm}$. Scale bar: $(\mathbf{a}, \mathbf{c}) 15 \mu \mathrm{m}$ and (b,d) $30 \mu \mathrm{m}$.

Author Contributions: Conceptualization, S.L.; formal analysis, S.L.; investigation, S.L.; methodology, B.S.; supervision, X.C.; writing—original draft, S.L.; writing—review and editing, X.C. All authors have read and agreed to the published version of the manuscript.

Funding: This work was supported by the National Key Research and Development Program of China (2017YFB0308600).

Institutional Review Board Statement: Not applicable.

Informed Consent Statement: Not applicable.

Data Availability Statement: The data presented in this study are available in supplementary material.

Acknowledgments: We thank the support by the National Key Research and Development Program of China.

Conflicts of Interest: The authors declare no conflict of interest. 


\section{References}

1. Fang, Y.; Miao, J.; Yang, X.; Zhu, Y.; Wang, G. Fabrication of polyphosphazene covalent triazine polymer with excellent flame retardancy and smoke suppression for epoxy resin. Chem. Eng. J. 2020, 385, 123830. [CrossRef]

2. Chen, L.; Wang, Y.-Z. A review on flame retardant technology in China. Part I: Development of flame retardants. Polym. Adv. Technol. 2009, 21, 1-26. [CrossRef]

3. Lu, S.; Zhou, W.; Yang, M.; Chen, G.; Hong, W.; Yu, D.; Zheng, Z.; Chen, X. Preparation and flame-retardant mechanism of polyheptazine/PA6 nanocmposites. Polym. 2019, 182, 121810. [CrossRef]

4. Chen, X.; Ma, C.; Jiao, C. Synergistic effects between iron-graphene and melamine salt of pentaerythritol phosphate on flame retardant thermoplastic polyurethane. Polym. Adv. Technol. 2016, 27, 1508-1516. [CrossRef]

5. Chen, X.; Zhang, X.; Wang, W.; Wang, Y.; Jiao, C. Fire-safe agent integrated with oyster shell and melamine polyphosphate for thermoplastic polyurethane. Polym. Adv. Technol. 2019, 30, 1576-1588. [CrossRef]

6. Wu, Z.; Xu, W.; Liu, Y.; Xia, J.; Wu, Q.; Xu, W. Preparation and Characterization of Flame-Retardant Melamine Cyanurate/Polyamide 6 Nanocomposites by in Situ Polymerization. J. Appl. Polym. Sci. 2009, 113, 2109-2116. [CrossRef]

7. Shi, Y.; Jiang, S.; Zhou, K.; Bao, C.; Yu, B.; Qian, X.; Wang, B.; Hong, N.; Wen, P.; Gui, Z.; et al. Influence of g-C3N4 Nanosheets on Thermal Stability and Mechanical Properties of Biopolymer Electrolyte Nanocomposite Films: A Novel Investigation. ACS Appl. Mater. Interfaces 2014, 6, 429-437. [CrossRef]

8. Shi, Y.; Long, Z.; Zhou, K.; Gui, Z.; Yu, B.; Yuen, K.K.R.; Hu, Y. Tunable thermal, flame retardant and toxic effluent suppression properties of polystyrene based on alternating graphitic carbon nitride and multi-walled carbon nanotubes. J. Mater. Chem. A 2015, 3, 17064-17073. [CrossRef]

9. Lu, S.; Hong, W.; Chen, X. Nanoreinforcements of Two-Dimensional Nanomaterials for Flame Retardant Polymeric Composites: An Overview. Adv. Polym. Technol. 2019, 2019, 1-25. [CrossRef]

10. Feng, Y.; Yunsheng, Y.; Wen, Y.; Ye, Y.S.; Zhou, X.; Xie, X.; Mai, Y.-W. Superior flame retardancy and smoke suppression of epoxy-based composites with phosphorus/nitrogen co-doped graphene. J. Hazard. Mater. 2018, 346, 140-151. [CrossRef]

11. Hu, S.; Ma, L.; You, J.; Li, F.; Fan, Z.; Wang, F.; Liu, D.; Gui, J. A simple and efficient method to prepare a phosphorus modified g-C3N4 visible light photocatalyst. RSC Adv. 2014, 4, 21657-21663. [CrossRef]

12. Velencoso, M.-M.; Battig, A.; Markwart, J.-C.; Schartel, B.; Wurm, F.-R. Molecular Firefighting-How Modern Phosphorus Chemistry Can Help Solve the Flame Retardancy Task. Angew. Chem. Int. Ed. 2018, 57, 10450-10467. [CrossRef] [PubMed]

13. Jiao, C.; Jiang, H.; Chen, X. Properties of fire agent integrated with molecular sieve and tetrafluoroborate ionic liquid in thermoplastic polyurethane elastomer. Polym. Adv. Technol. 2019, 30, 2159-2167. [CrossRef]

14. Mandlekar, N.; Cayla, A.; Rault, F.; Giraud, S.; Salaün, F.; Guan, J. Development of Novel Polyamide 11 Multifilaments and Fabric Structures Based on Industrial Lignin and Zinc Phosphinate as Flame Retardants. Molecules 2020, 25, 4963. [CrossRef]

15. Huang, S.-C.; Deng, C.; Chen, H.; Li, Y.-M.; Zhao, Z.-Y.; Wang, S.-X.; Wang, Y.-Z. Novel Ultrathin Layered Double Hydroxide Nanosheets with In Situ Formed Oxidized Phosphorus as Anions for Simultaneous Fire Resistance and Mechanical Enhancement of Thermoplastic Polyurethane. ACS Appl. Polym. Mater. 2019, 1, 1979-1990. [CrossRef]

16. Zhou, Q.; Gong, K.; Zhou, K.; Zhao, S.; Shi, C. Synergistic effect between phosphorus tailings and aluminum hypophosphite in flame-retardant thermoplastic polyurethane composites. Polym. Adv. Technol. 2019, 30, 2480-2487. [CrossRef]

17. Zhou, Q.; Liu, C.; Zhou, K.; Xuan, X.; Shi, C. Synergistic effect between solid wastes and intumescent flame retardant on flammability and smoke suppression of thermoplastic polyurethane composites. Polym. Adv. Technol. 2020, 31, 4-14. [CrossRef]

18. Jamain, Z.; Khairuddean, M.; Guan-Seng, T. Liquid-Crystal and Fire-Retardant Properties of New Hexasubstituted Cyclotriphosphazene Compounds with Two Schiff Base Linking Units. Molecules 2020, 25, 2122. [CrossRef]

19. Hu, C.; Wang, M.-S.; Chen, C.-H.; Chen, Y.-R.; Huang, P.-H.; Tung, K.-L. Phosphorus-doped g-C3N4 integrated photocatalytic membrane reactor for wastewater treatment. J. Membr. Sci. 2019, 580, 1-11. [CrossRef]

20. Fang, H.-B.; Zhang, X.-H.; Wu, J.; Li, N.; Zheng, Y.-Z.; Tao, X. Fragmented phosphorus-doped graphitic carbon nitride nanoflakes with broad sub-bandgap absorption for highly efficient visible-light photocatalytic hydrogen evolution. Appl. Catal. B Environ. 2018, 225, 397-405. [CrossRef]

21. Guo, S.; Tang, Y.; Xie, Y.; Tian, C.; Feng, Q.; Zhou, W.; Jiang, B. P-Doped Tubular G-C3N4 with Surface Carbon Defects: Uni-versal Synthesis and Enhanced Visible-Light Photocatalytic Hydrogen Production. Appl. Catal. B 2017, 218, 664-671. [CrossRef]

22. Zhu, M.; Yu, S.; Ge, R.; Feng, L.; Yu, Y.; Li, Y.; Li, W. Cobalt Oxide Supported on Phosphorus-Doped g-C3N4 as an Efficient Electrocatalyst for Oxygen Evolution Reaction. ACS Appl. Energy Mater. 2019, 2, 4718-4729. [CrossRef]

23. Hasija, V.; Sudhaik, A.; Raizada, P.; Hosseini-Bandegharaei, A.; Singh, P. Carbon Quantum Dots Supported AgI/ZnO/Phosphorus Doped Graphitic Carbon Nitride as Z-Scheme Photocatalyst for Efficient Photodegradation of 2, 4-Dinitrophenol. J. Environ. Chem. Eng. 2019, 7, 103272. [CrossRef]

24. Deng, Y.; Tang, L.; Zeng, G.; Zhu, Z.; Yan, M.; Zhou, Y.; Wang, J.; Liu, Y.; Wang, J. Insight Into Highly Efficient Simultaneous Photocatalytic Removal of $\mathrm{Cr}(\mathrm{Vi})$ and 2,4-Diclorophenol Under Visible Light Irradiation by Phosphorus Doped Porous Ul-trathin G-C3N4 Nanosheets From Aqueous Media: Performance and Reaction Mechanism. Appl. Catal. B 2017, 203, 343-354. [CrossRef]

25. Rong, M.; Cai, Z.; Xie, L.; Lin, C.; Song, X.; Luo, F.; Wang, Y.; Chen, X. Study on the Ultrahigh Quantum Yield of Fluorescent P,O-g-C3N4Nanodots and its Application in Cell Imaging. Chem. A Eur. J. 2016, 22, 9387-9395. [CrossRef] [PubMed]

26. Lin, M.; Li, B.; Li, Q.; Li, S.; Zhang, S. Synergistic effect of metal oxides on the flame retardancy and thermal degradation of novel intumescent flame-retardant thermoplastic polyurethanes. J. Appl. Polym. Sci. 2011, 121, 1951-1960. [CrossRef] 
27. Ramgobin, A.; Fontaine, G.; Penverne, C.; Bourbigot, S. Thermal Stability and Fire Properties of Salen and Metallosalens as Fire Retardants in Thermoplastic Polyurethane (TPU). Materials 2017, 10, 665. [CrossRef]

28. Shi, Y.; Hu, Y.; Zhou, K.; Yuen, R.K.; Gui, Z.; Saihua, J.; Jiang, S. Novel CuCo2O4/graphitic carbon nitride nanohybrids: Highly effective catalysts for reducing $\mathrm{CO}$ generation and fire hazards of thermoplastic polyurethane nanocomposites. J. Hazard. Mater. 2015, 293, 87-96. [CrossRef]

29. Shi, Y.; Gui, Z.; She, S.; Zhu, Y.; Yu, B.; Yuen, K.K.R.; Liu, H.; Hu, Y. Enhanced thermal stability of polystyrene by graphitic carbon nitride/spinel ZnCo $2 \mathrm{O} 4$ nanohybrids and the catalytic mechanism investigation. RSC Adv. 2015, 5, 41835-41838. [CrossRef]

30. Hou, Y.; Hu, W.; Gui, Z.; Hu, Y. Preparation of Metal-Organic Frameworks and Their Application as Flame Retardants for Polystyrene. Ind. Eng. Chem. Res. 2017, 56, 2036-2045. [CrossRef]

31. Xu, W.; Chen, R.; Du, Y.; Wang, G. Design Water-Soluble Phenolic/Zeolitic Imidazolate Framework-67 Flame Retardant Coating Via Layer-by-Layer Assembly Technology: Enhanced Flame Retardancy and Smoke Suppression of Flexible Polyure-thane Foam. Polym. Degrad. Stabil. 2020, 176, 109152. [CrossRef]

32. Zhou, K.; Gui, Z.; Hu, Y.; Jiang, S.; Tang, G. The influence of cobalt oxide-graphene hybrids on thermal degradation, fire hazards and mechanical properties of thermoplastic polyurethane composites. Compos. Part A Appl. Sci. Manuf. 2016, 88, 10-18. [CrossRef]

33. Tan, H.; Tang, J.; Henzie, J.; Li, Y.; Xu, X.; Chen, T.; Wang, Z.; Wang, J.; Ide, Y.; Bando, Y.; et al. Assembly of Hollow Carbon Nanospheres on Graphene Nanosheets and Creation of Iron-Nitrogen-Doped Porous Carbon for Oxygen Reduction. ACS Nano 2018, 12, 5674-5683. [CrossRef] [PubMed]

34. Tahir, M.; Mahmood, N.; Pan, L.; Huang, Z.-F.; Lv, Z.; Zhang, J.; Butt, F.K.; Shen, G.; Zhang, X.; Dou, S.X.; et al. Efficient water oxidation through strongly coupled graphitic C3N4 coated cobalt hydroxide nanowires. J. Mater. Chem. A 2016, 4, 12940-12946. [CrossRef]

35. Xue, F.; Si, Y.; Wang, M.; Liu, M.; Guo, L. Toward efficient photocatalytic pure water splitting for simultaneous $\mathrm{H} 2$ and $\mathrm{H} 2 \mathrm{O} 2$ production. Nano Energy 2019, 62, 823-831. [CrossRef]

36. Zhang, Y.; Mori, T.; Ye, J.; Antonietti, M. Phosphorus-Doped Carbon Nitride Solid: Enhanced Electrical Conductivity and Photocurrent Generation. J. Am. Chem. Soc. 2010, 132, 6294-6295. [CrossRef]

37. Zhou, Y.; Zhang, L.; Liu, J.; Fan, X.; Wang, B.; Wang, M.; Ren, W.; Wang, J.; Li, M.; Shi, J. Brand New P-Doped G-C3N4: En-hanced Photocatalytic Activity for H2 Evolution and Rhodamine B Degradation under Visible Light. J. Mater. Chem. A 2015, 3, 3862-3867. [CrossRef]

38. Wang, B.; Cai, H.; Zhao, D.; Song, M.; Guo, P.; Shen, S.; Li, D.; Yang, S. Enhanced photocatalytic hydrogen evolution by partially replaced corner-site C atom with P in g-C3N4. Appl. Catal. B Environ. 2019, 244, 486-493. [CrossRef]

39. Feng, J.; Zhang, D.; Zhou, H.; Pi, M.; Wang, X.; Chen, S. Coupling P Nanostructures with P-Doped g-C3N4 As Efficient Visible Light Photocatalysts for H2 Evolution and RhB Degradation. ACS Sustain. Chem. Eng. 2018, 6, 6342-6349. [CrossRef]

40. Bellardita, M.; García-López, E.I.; Marcì, G.; Krivtsov, I.; García, J.R.; Palmisano, L. Selective photocatalytic oxidation of aromatic alcohols in water by using P-doped g-C3N4. Appl. Catal. B Environ. 2018, 220, 222-233. [CrossRef]

41. Qiu, P.; Xu, C.; Zhou, N.; Chen, H.; Jiang, F. Metal-free black phosphorus nanosheets-decorated graphitic carbon nitride nanosheets with C P bonds for excellent photocatalytic nitrogen fixation. Appl. Catal. B Environ. 2018, 221, 27-35. [CrossRef]

42. Wang, S.; He, F.; Zhao, X.; Zhang, J.; Ao, Z.; Wu, H.; Yin, Y.; Shi, L.; Xu, X.; Zhao, C.; et al. Phosphorous doped carbon nitride nanobelts for photodegradation of emerging contaminants and hydrogen evolution. Appl. Catal. B Environ. 2019, 257, 117931. [CrossRef]

43. Zhao, C.; Wang, S.; Yan, Q.; Dong, P.; Wang, Y.; Liu, F.; Li, L. Nitrogen Defects-Rich 0D/2D $\alpha$-Fe2O3/g-C3N4 Z-Scheme Pho-tocatalyst for Enhanced Photooxidation and H2 Evolution Efficiencies. Nano 2018, 13, 1850086. [CrossRef]

44. Han, Q.; Wang, B.; Gao, J.; Qu, L. Graphitic Carbon Nitride/Nitrogen-Rich Carbon Nanofibers: Highly Efficient Photocatalytic Hydrogen Evolution without Cocatalysts. Angew. Chem. Int. Ed. 2016, 55, 10849-10853. [CrossRef] [PubMed]

45. Martin, D.J.; Qiu, K.; Shevlin, S.A.; Handoko, A.D.; Chen, X.; Guo, Z.; Tang, J. Highly Efficient Photocatalytic H2Evolution from Water using Visible Light and Structure-Controlled Graphitic Carbon Nitride. Angew. Chem. Int. Ed. 2014, 53, 9240-9245. [CrossRef] [PubMed]

46. Fu, X.; Choi, J.-Y.; Zamani, P.; Jiang, G.; Hoque, A.; Hassan, F.M.; Chen, Z. Co-N Decorated Hierarchically Porous Graphene Aerogel for Efficient Oxygen Reduction Reaction in Acid. ACS Appl. Mater. Interfaces 2016, 8, 6488-6495. [CrossRef]

47. Zhu, Y.-P.; Ren, T.-Z.; Yuan, Z.-Y. Mesoporous Phosphorus-Doped g-C3N4 Nanostructured Flowers with Superior Photocatalytic Hydrogen Evolution Performance. ACS Appl. Mater. Interfaces 2015, 7, 16850-16856. [CrossRef]

48. Liu, L.; Jiang, Z.; Fang, L.; Xu, H.; Zhang, H.; Gu, X.; Wang, Y. Probing the Crystal Plane Effect of Co3O4 for Enhanced Electrocatalytic Performance Toward Efficient Overall Water Splitting. ACS Appl. Mater. Interfaces 2017, 9, 27736-27744. [CrossRef]

49. Li, X.; Zhang, L.; Huang, M.; Wang, S.; Li, X.; Zhu, H. Cobalt and nickel selenide nanowalls anchored on graphene as bifunctional electrocatalysts for overall water splitting. J. Mater. Chem. A 2016, 4, 14789-14795. [CrossRef]

50. Tao, L.; Lin, C.-Y.; Dou, S.; Feng, S.; Chen, D.; Liu, D.; Huo, J.; Xia, Z.; Wang, S. Creating coordinatively unsaturated metal sites in metal-organic-frameworks as efficient electrocatalysts for the oxygen evolution reaction: Insights into the active centers. Nano Energy 2017, 41, 417-425. [CrossRef]

51. Pylypenko, S.; Mukherjee, S.; Olson, T.S.; Atanassov, P. Non-platinum oxygen reduction electrocatalysts based on pyrolyzed transition metal macrocycles. Electrochim. Acta 2008, 53, 7875-7883. [CrossRef] 
52. Chen, X.; Jiang, Y.; Jiao, C. Smoke suppression properties of ferrite yellow on flame retardant thermoplastic polyurethane based on ammonium polyphosphate. J. Hazard. Mater. 2014, 266, 114-121. [CrossRef]

53. Tao, K.; Li, J.; Xu, L.; Zhao, X.; Xue, L.; Fan, X.; Yan, Q. A novel phosphazene cyclomatrix network polymer: Design, synthesis and application in flame retardant polylactide. Polym. Degrad. Stab. 2011, 96, 1248-1254. [CrossRef]

54. Liu, H.; Wang, X.; Wu, D. Novel cyclotriphosphazene-based epoxy compound and its application in halogen-free epoxy thermosetting systems: Synthesis, curing behaviors, and flame retardancy. Polym. Degrad. Stab. 2014, 103, 96-112. [CrossRef]

55. Formicola, C.; De Fenzo, A.; Zarrelli, M.; Giordano, M.; Antonucci, V. Zinc-based compounds as smoke suppressant agents for an aerospace epoxy matrix. Polym. Int. 2010, 60, 304-311. [CrossRef]

56. Fei, B.; Tawiah, B.; Wang, L.-Q.; Yuen, A.; Zhang, Z.-C.; Shen, L.-L.; Lin, B.; Fei, B.; Yang, W.; Li, A.; et al. Interface decoration of exfoliated MXene ultra-thin nanosheets for fire and smoke suppressions of thermoplastic polyurethane elastomer. J. Hazard. Mater. 2019, 374, 110-119. [CrossRef]

57. Wang, J.; Zhang, D.; Zhang, Y.; Cai, W.; Yao, C.; Hu, Y.; Hu, W. Construction of multifunctional boron nitride nanosheet towards reducing toxic volatiles $(\mathrm{CO}$ and $\mathrm{HCN})$ generation and fire hazard of thermoplastic polyurethane. J. Hazard. Mater. 2019, 362, 482-494. [CrossRef]

58. Wang, S.; Gao, R.; Zhou, K. The influence of cerium dioxide functionalized reduced graphene oxide on reducing fire hazards of thermoplastic polyurethane nanocomposites. J. Colloid Interface Sci. 2019, 536, 127-134. [CrossRef]

59. Shi, Y.; Wang, L.; Fu, L.; Liu, C.; Yu, B.; Yang, F.; Hu, Y. Sodium Alginate-Templated Synthesis of g-C3N4/Carbon Spheres/Cu Ternary Nanohybrids for Fire Safety Application. J. Colloid Interface Sci. 2019, 539, 1-10. [CrossRef]

60. Wei, W.-C.; Deng, C.; Huang, S.-C.; Wei, Y.-X.; Wang, Y.-Z. Nickel-Schiff base decorated graphene for simultaneously enhancing the electroconductivity, fire resistance, and mechanical properties of a polyurethane elastomer. J. Mater. Chem. A 2018, 6, 8643-8654. [CrossRef]

61. Wang, J.; Hu, Y.; Cai, W.; Yuan, B.; Zhang, Y.; Guo, W.; Hu, W.; Song, L. Atherton-Todd reaction assisted synthesis of functionalized multicomponent MoSe2/CNTs nanoarchitecture towards the fire safety enhancement of polymer. Compos. Part A Appl. Sci. Manuf. 2018, 112, 271-282. [CrossRef]

62. Cai, W.; Wang, J.; Pan, Y.; Guo, W.; Mu, X.; Feng, X.; Yuan, B.; Wang, X.; Hu, Y. Mussel-Inspired Functionalization of Electrochemically Exfoliated Graphene: Based on Self-Polymerization of Dopamine and its Suppression Effect on the Fire Hazards and Smoke Toxicity of Thermoplastic Polyurethane. J. Hazard. Mater. 2018, 352, 57-69. [CrossRef] [PubMed]

63. Wang, J.; Ma, C.; Mu, X.; Cai, W.; Liu, L.; Zhou, X.; Hu, W.; Hu, Y. Construction of multifunctional MoSe2 hybrid towards the simultaneous improvements in fire safety and mechanical property of polymer. J. Hazard. Mater. 2018, 352, 36-46. [CrossRef] [PubMed] 